\title{
initMIP-Antarctica: an ice sheet model initialization experiment of ISMIP6
}

Hélène Seroussi ${ }^{1}$, Sophie Nowicki ${ }^{2}$, Erika Simon $^{2}$, Ayako Abe-Ouchi ${ }^{3}$, Torsten Albrecht ${ }^{4}$, Julien Brondex $^{5}$, Stephen Cornford $^{6}$, Christophe Dumas ${ }^{7}$, Fabien Gillet-Chaulet ${ }^{5}$, Heiko Goelzer ${ }^{8,9}$, Nicholas R. Golledge ${ }^{10}$, Jonathan M. Gregory ${ }^{11}$, Ralf Greve ${ }^{12}$, Matthew J. Hoffman ${ }^{13}$, Angelika Humbert ${ }^{14,15}$, Philippe Huybrechts ${ }^{16}$, Thomas Kleiner $^{14}$, Eric Larour ${ }^{1}$, Gunter Leguy ${ }^{17}$, William H. Lipscomb ${ }^{17}$, Daniel Lowry ${ }^{10}$, Matthias Mengel ${ }^{4}$, Mathieu Morlighem ${ }^{18}$, Frank Pattyn ${ }^{9}$, Anthony J. Payne ${ }^{19}$, David Pollard ${ }^{20}$, Stephen F. Price ${ }^{13}$, Aurélien Quiquet ${ }^{7}$, Thomas J. Reerink $^{8,21}$, Ronja Reese ${ }^{4}$, Christian B. Rodehacke ${ }^{22,14}$, Nicole-Jeanne Schlegel ${ }^{1}$, Andrew Shepherd ${ }^{23}$, Sainan Sun ${ }^{9}$, Johannes Sutter ${ }^{14,26}$, Jonas Van Breedam ${ }^{16}$, Roderik S. W. van de Wal ${ }^{8,24}$, Ricarda Winkelmann ${ }^{4,25}$, and Tong Zhang ${ }^{13}$

${ }^{1}$ Jet Propulsion Laboratory, California Institute of Technology, Pasadena, CA, USA

${ }^{2}$ NASA Goddard Space Flight Center, Greenbelt, MD, USA

${ }^{3}$ University of Tokyo, Tokyo, Japan

${ }^{4}$ Potsdam Institute for Climate Impact Research (PIK), Member of the Leibniz Association, Potsdam, Germany

${ }^{5}$ Univ. Grenoble Alpes, CNRS, IRD, Grenoble INP, IGE, 38000 Grenoble, France

${ }^{6}$ Swansea University, Swansea, UK

${ }^{7}$ Laboratoire des Sciences du Climat et de l'Environnement, LSCE/IPSL, CEA-CNRS-UVSQ,

Université Paris-Saclay, 91191 Gif-sur-Yvette, France

${ }^{8}$ Institute for Marine and Atmospheric research Utrecht, Utrecht University, Utrecht, the Netherlands

${ }^{9}$ Laboratoire de Glaciologie, Université libre de Bruxelles, Brussels, Belgium

${ }^{10}$ Antarctic Research Centre, Victoria University of Wellington, Wellington, New Zealand

${ }^{11}$ National Center for Atmospheric Science, University of Reading, Reading, UK

${ }^{12}$ Institute of Low Temperature Science, Hokkaido University, Sapporo, Japan

${ }^{13}$ Fluid Dynamics and Solid Mechanics Group, Los Alamos National Laboratory, Los Alamos, NM 87545, USA

${ }^{14}$ Alfred Wegener Institute Helmholtz Centre for Polar and Marine Research, Bremerhaven, Germany

${ }^{15}$ Department of Geoscience, University of Bremen, Bremen, Germany

${ }^{16}$ Earth System Science \& Departement Geografie, Vrije Universiteit Brussel, Brussels, Belgium

${ }^{17}$ Climate and Global Dynamics Laboratory, National Center for Atmospheric Research, Boulder, CO, USA

${ }^{18}$ Department of Earth System Science, University of California Irvine, Irvine, CA, USA

${ }^{19}$ University of Bristol, Bristol, UK

${ }^{20}$ Earth and Environmental Systems Institute, Pennsylvania State University, University Park, PA, USA

${ }^{21}$ Royal Netherlands Meteorological Institute (KNMI), De Bilt, the Netherlands

${ }^{22}$ Danish Meteorological Institute, Arctic and Climate, Copenhagen, Denmark

${ }^{23}$ University of Leeds, Leeds, UK

${ }^{24}$ Geosciences, Physical Geography, Utrecht University, Utrecht, the Netherlands

${ }^{25}$ University of Potsdam, Institute of Physics and Astronomy, Potsdam, Germany

${ }^{26}$ Climate and Environmental Physics, Physics Institute, and Oeschger Centre for Climate Change Research, University of Bern, Bern, Switzerland

Correspondence: Hélène Seroussi (helene.seroussi@jpl.nasa.gov)

Received: 8 December 2018 - Discussion started: 17 January 2019

Revised: 18 March 2019 - Accepted: 24 April 2019 - Published: 14 May 2019

Published by Copernicus Publications on behalf of the European Geosciences Union. 


\begin{abstract}
Ice sheet numerical modeling is an important tool to estimate the dynamic contribution of the Antarctic ice sheet to sea level rise over the coming centuries. The influence of initial conditions on ice sheet model simulations, however, is still unclear. To better understand this influence, an initial state intercomparison exercise (initMIP) has been developed to compare, evaluate, and improve initialization procedures and estimate their impact on century-scale simulations. initMIP is the first set of experiments of the Ice Sheet Model Intercomparison Project for CMIP6 (ISMIP6), which is the primary Coupled Model Intercomparison Project Phase 6 (CMIP6) activity focusing on the Greenland and Antarctic ice sheets. Following initMIP-Greenland, initMIP-Antarctica has been designed to explore uncertainties associated with model initialization and spin-up and to evaluate the impact of changes in external forcings. Starting from the state of the Antarctic ice sheet at the end of the initialization procedure, three forward experiments are each run for 100 years: a control run, a run with a surface mass balance anomaly, and a run with a basal melting anomaly beneath floating ice. This study presents the results of initMIP-Antarctica from 25 simulations performed by 16 international modeling groups. The submitted results use different initial conditions and initialization methods, as well as ice flow model parameters and reference external forcings. We find a good agreement among model responses to the surface mass balance anomaly but large variations in responses to the basal melting anomaly. These variations can be attributed to differences in the extent of ice shelves and their upstream tributaries, the numerical treatment of grounding line, and the initial ocean conditions applied, suggesting that ongoing efforts to better represent ice shelves in continental-scale models should continue.
\end{abstract}

\section{Introduction}

The Antarctic ice sheet is the largest reservoir of freshwater on Earth and contains enough ice to raise global mean sea level by $58.3 \mathrm{~m}$ (Fretwell et al., 2013). Reconstructions of past sea-level variations show that the volume of the Antarctic ice sheet has varied significantly over time, with for example an ice loss of up to $15 \mathrm{~m}$ sea level equivalent (SLE) at a rate of up to $1 \mathrm{~mm} \mathrm{yr}^{-1}$ during the Pliocene, around 5.32.6 million years before present (Miller et al., 2012). Several regions of the Antarctic ice sheet are currently changing rapidly (Rott et al., 2002; Scambos et al., 2004; De Angelis and Skvarca, 2003; Khazendar et al., 2013; Mouginot et al., 2014; Rignot et al., 2014; Christie et al., 2016). These changes have been attributed to changes in ocean circulation (e.g., Thomas et al., 2004; Payne et al., 2004; Jenkins et al., 2010, 2018; Jacobs et al., 2012) and atmospheric conditions (e.g., Doake and Vaughan, 1991; Vaughan and Doake, 1996; Scambos et al., 2000). Understanding how the Antarctic ice sheet will evolve over the coming centuries, and in particular how much it will contribute to sea level, has therefore become a major field of research.

Projections of 21st century Antarctic ice sheet evolution, however, vary widely, with projected upper bounds ranging from $30 \mathrm{~cm}$ of sea level equivalent (Ritz et al., 2015) to over $1 \mathrm{~m}$ (DeConto and Pollard, 2016), depending on model characteristics and physical processes, as well as the climate scenarios adopted. Previous efforts from the ice sheet modeling community for the IPCC-AR5 (Intergovernmental Panel for Climate Change Fifth Assessment Report; Church et al., 2013) tried to estimate the ice sheet evolution under several climate scenarios (Bindschadler et al., 2013; Nowicki et al., 2013a, b). These results had a large spread for all scenarios, as a consequence of differences in model characteristics and processes included, initialization methods, and the interpretation and application of model forcings (Nowicki et al., 2013b).

A limitation of these previous efforts was the use of climate forcing that could be considered as outdated by the time of the experiments. For example, the SeaRISE initiative (Sea level Response to Ice Sheet Evolution; Bindschadler et al., 2013) used results from IPCC-AR4 scenarios, while at the same time IPCC-AR5 climate simulations became available. In order to better coordinate the ice sheet modeling and climate modeling communities, the Ice Sheet Model Intercomparison Project for CMIP6 (ISMIP6) was designed to be the primary activity within the Coupled Model Intercomparison Project Phase 6 (CMIP6) that focuses on the Greenland and Antarctic ice sheets (Nowicki et al., 2016).

Previous ice sheet intercomparison efforts (Pattyn et al., 2012, 2013; Bindschadler et al., 2013; Goelzer et al., 2018) highlighted the importance of better assessing the causes of the spread in model results and separating differences associated with model grid resolution, ice dynamics (e.g., choice of stress balance equation), physical processes included (e.g., calving, hydrofracture, and cliff failure), and initialization procedure (e.g., data assimilation, spin-up, or relaxation). While the impact of many processes and parameters can be assessed by running large ensembles (e.g., Ritz et al., 2015; Pollard et al., 2016) or using uncertainty quantification (e.g., Schlegel et al., 2013, 2015, 2018), analyzing the impact of initial conditions is more difficult. Ice sheet models rely primarily on two methods to construct their initial state: (1) long transient simulations of ice sheet evolution since the Last Glacial Maximum or earlier, with forcing based on past climates (e.g., Huybrechts, 2002; Greve and Herzfeld, 2013; Aschwanden et al., 2013; Golledge et al., 2015), or (2) data assimilation of observed present-day conditions at a given time (e.g., Morlighem et al., 2010, 2013; Gillet-Chaulet et al., 2012; Favier et al., 2014; Arthern et al., 2015; Cornford et al., 2015). The first captures the climate history and ensures that modeled variables are mutually consistent, but the sim- 
ulated present-day ice state might differ significantly from the current observed state, which can impact the sensitivity to perturbations (Pollard and DeConto, 2012a). The second method reproduces present-day ice sheet geometry and velocity well but does not capture past climate evolution and current trends of ice mass, due to inconsistencies between datasets (Seroussi et al., 2011), also impacting the ice sheet response to perturbations. To combine the best of these two approaches, models using long transient spin-ups have integrated simple inverse methods to match present ice sheet geometry (Pollard and DeConto, 2012a), while models using data assimilation have run short-term relaxation periods to limit the initial shock caused by inconsistent datasets (GilletChaulet et al., 2012). These additions are widening the spectrum of initialization methods (see also Goelzer et al., 2018).

Since ice sheets have a slow response time, their initial conditions influence their evolution for centuries to millennia. Understanding the impact of initialization methods is therefore critical for projections of sea level in the 21st century and beyond. The initMIP experiments were thus designed as the first part of ISMIP6, with the goal of understanding the effects of initialization procedures on model results under simplified and relatively large climate forcings. This effort is intended to show the impact of model initial conditions on the variations in sea level contribution from Antarctica but not to provide improved estimates of sea level evolution. A previous effort, initMIP-Greenland (Goelzer et al., 2018), showed that the initial ice sheet extent has a large impact on Greenland ice sheet evolution when anomalies in surface mass balance (SMB) are applied. Here, we describe a similar effort for the Antarctic ice sheet, using simple climate anomalies applied to both the SMB and to sub-ice-shelf melting rates. We analyze 25 simulations from 16 international groups in order to determine the most relevant factors and to better understand the spread in projections of 21 st century Antarctic ice sheet contributions to sea level.

We first describe the initMIP-Antarctica experimental design in Sect. 2 and the participating models in Sect. 3. In Sect. 4, we analyze simulation results and the spread in model responses, and in Sect. 5 we discuss these results and their implications for improving model initialization and constraining sea-level projections. We conclude with remarks relevant to future modeling efforts.

\section{Experiments and model setup}

In this section we describe in detail the initMIP-Antarctica experiments, including model requirements and outputs. Complete documentation can be found on the ISMIP6 wiki page (http://www.climate-cryosphere.org/wiki/index. php?title=InitMIP-Antarctica, last access: 7 May 2019).

\subsection{Experiments description}

InitMIP-Antarctica consists of an initial state, init, describing the initial state of the Antarctic ice sheet model, followed by three experiments, each designed for continentalscale Antarctic simulations. Modeling groups are asked to describe the ice sheet geometry and other characteristics at the end of their initialization procedure, which is left to the discretion of each group. The following three experiments are 100-year simulations of the Antarctica ice sheet evolution under different forcing scenarios.

In $\mathrm{ctrl}$, the control run, climate forcing is assumed to be similar to present-day conditions, so atmospheric and oceanic forcings at the end of the init experiment are continued unchanged. The total SMB or basal melt applied to the ice sheet can however change, due to, e.g., variations in ice extent during the ctrl simulation.

In $a s m b$, the SMB anomaly experiment, atmospheric forcing evolves under a climate-change scenario associated with high greenhouse gas emissions, similar to Representative Concentration Pathway (RCP) 8.5. The prescribed anomaly is the average change in Antarctic SMB for six models: five publicly available CMIP5 RCP8.5 model simulations (Taylor et al., 2012) with large SMB changes between 2006-2010 and 2095-2100, along with one regional model (RACMO2.1; Ligtenberg et al., 2013). As RACMO2.1 results for RCP8.5 were not available when the anomaly field was prepared, we used results for the A1B scenario, with SMB adjusted linearly to reflect the additional radiative forcing (an increase of $8.5 \mathrm{~W} \mathrm{~m}^{-2}$ by 2100 in RCP8.5, compared to $6 \mathrm{~W} \mathrm{~m}^{-2}$ in $\left.\mathrm{A} 1 \mathrm{~B}\right)$. The RCP8.5 scenario increases precipitation by up to $50 \%$ over the Antarctic ice sheet for some climate models (Ligtenberg et al., 2013; Palerme et al., 2016). SMB anomalies are mostly positive over the ice sheet, with a few regions seeing a negative anomaly due to increased surface runoff (Fig. 1a). This anomaly is applied over the entire ice sheet.

In $a b m b$, an anomaly in ocean-induced sub-ice-shelf melt rates is applied under the floating ice to mimic future warming of ocean waters. It is not well understood how changes in far-field ocean conditions in global climate models transfer onto the Antarctic continental shelf and into sub-iceshelf cavities; this is an active area of research (Nakayama et al., 2014; Asay-Davis et al., 2017; Donat-Magnin et al., 2017). We therefore apply a simple forcing anomaly equivalent to the estimated present-day melt rates under floating ice (Depoorter et al., 2013; Rignot et al., 2013). The melt rate anomaly is the average between these two datasets and averaged over ice shelves in each of the 20 ice sheet basins defined, so that a different mean melt rate anomaly is specified for each of the 20 ice sheet basins, with a spatially uniform anomaly within each basin (Fig. 1b). Thus, this melt rate anomaly represents a doubling of present-day estimates of melting. The anomaly is applied under all floating ice, including ice that ungrounds during the experiment. 
For the asmb and abmb experiments, anomalies in SMB and sub-shelf melt rates are applied in addition to the forcings used in the init and ctrl experiments. The anomalies are applied as time-dependent functions, increasing stepwise each year over the first 40 simulation years and remaining constant over the last 60 years:

$\mathrm{EX}(t)=\mathrm{EX}_{\mathrm{ctrl}}+\mathrm{EX}_{\text {anom }} \times \frac{[t]}{40} ;$ for $0<t<40$ years

$\mathrm{EX}(t)=\mathrm{EX}_{\mathrm{ctrl}}+\mathrm{EX}_{\mathrm{anom}}$; for $t>40$ years,

where $\operatorname{EX}(t)$ is the forcing at time $t, \operatorname{EX}_{\text {ctrl }}$ the forcing used in the ctrl experiment, $\mathrm{EX}_{\text {anom }}$ the applied anomaly (Fig. 1), and $[t]$ the floor function at time $t$.

These forcings should not be viewed as projections of climate forcing over the coming century, but rather they represent simple perturbations with relatively large changes for the purpose of assessing impacts on Antarctic ice sheet evolution.

\subsection{Model setup}

Ice sheet models are free to use whatever initialization procedure is deemed appropriate, given model characteristics and requirements. Submitted simulations rely on long paleoclimate spin-ups, steady states, data assimilation, or a combination of these methods. There is no constraint or suggestion on forcing datasets (including SMB and sub-shelf melt rates) or on specific physical processes and parameterizations (e.g., basal sliding laws, ice rheology, and stress balance approximation). The initialization time varies among models but is near the beginning of the 21 st century.

Previous multi-model ice sheet studies (Bindschadler et al., 2013; Nowicki et al., 2013a, b) showed the difficulty of separating the effects of initial conditions, physical processes, and external forcings. In order to better analyze the links between initial conditions and external forcings, we impose several modeling constraints. Models are required to model floating ice shelves and grounding line dynamics as changes in ice shelves significantly impacted the evolution of West Antarctica in the past decades. The exact procedure to simulate these processes, however, is left at the discretion of the modeling groups. Ice sheet models should apply the provided SMB anomalies without adjusting for geometric changes in forward experiments (i.e., surface-elevation feedback). Similarly, they should apply the basal melt rate anomaly under floating ice as it evolves over time. Finally, bedrock elevation adjustment, ice shelf hydrofracturing, and ice cliff failure should not be included, while the ice front evolution is left at the discretion of the modeling groups.

\subsection{Model outputs}

Modeling groups were requested to report simulation results using a standard output format. Table A1 lists the required outputs, including both scalar and 2-D variables. Scalar vari- ables are values describing the entire ice sheet (e.g., ice mass, ice mass above floatation, and area-integrated SMB and basal melting). Three kinds of 2-D outputs are requested. State variables (e.g., ice velocity and thickness) are snapshots reported at a given time; flux variables are reported as temporal averages over a given period; and constant variables do not change with time.

Scalar outputs are provided for each simulation year and corrected for area distortion due to the projection (e.g., polar stereographic), while 2-D variables (e.g., ice thickness, surface temperature, and basal drag) are reported every 5 years. For 2-D variables, results are reported on prescribed regular grids to help achieve a consistent analysis. These grids are defined on a polar stereographic projection with standard parallel $71^{\circ} \mathrm{S}$ and central meridian $0^{\circ} \mathrm{E}$. Modelers are free to use one of the six prescribed grids with the resolution closest to their native resolution. All outputs are then regridded using a conservative interpolation scheme (Jones, 1999) onto an $8 \mathrm{~km}$ grid that is used for the analysis. The output grids are identical to the grids used to provide the SMB and basal melt anomalies.

\section{Participating models}

Sixteen modeling centers participated in the initMIPAntarctica effort and submitted 25 simulations; each model performed the whole suite of experiments. The list of modeling centers is shown in Table 1. Table 2 lists the main characteristics of each simulation, including the stress balance approximation, grid resolution, initialization procedure, initial year, and external forcing. More details on individual models and initialization procedures can be found in Appendix B.

The majority of models use the finite-difference method, with two models based on finite volumes, two based on the finite-element method, and two based on a combination of finite element and finite volume. Two simulations use the Shallow Shelf Approximation (SSA; MacAyeal, 1989), three use L1L2 (i.e. depth-integrated higher-order) approximations (Hindmarsh, 2004), and two use a 3-D higher-order approximation (Pattyn, 2003). The other models use a combination of the Shallow Ice Approximation (SIA; Hutter, 1983) and SSA, either combining SIA for the grounded ice with SSA for the floating ice or using SSA as a sliding law and SIA for the internal deformation (Bueler and Brown, 2009). The grid resolution ranges from 4 to $32 \mathrm{~km}$ for models based on fixed regular grids, while models using adaptive grid refinement are able to use resolutions as low as $0.5 \mathrm{~km}$ in grounding zones.

The initialization methods cover the spectrum of procedures used in the ice sheet modeling community. Fourteen simulations are based on a paleoclimate spin-up with forcings reproducing the evolution of climate during the simulated period, and four of these simulations have a targeted ice sheet geometry at the end of their run, similar to the method 

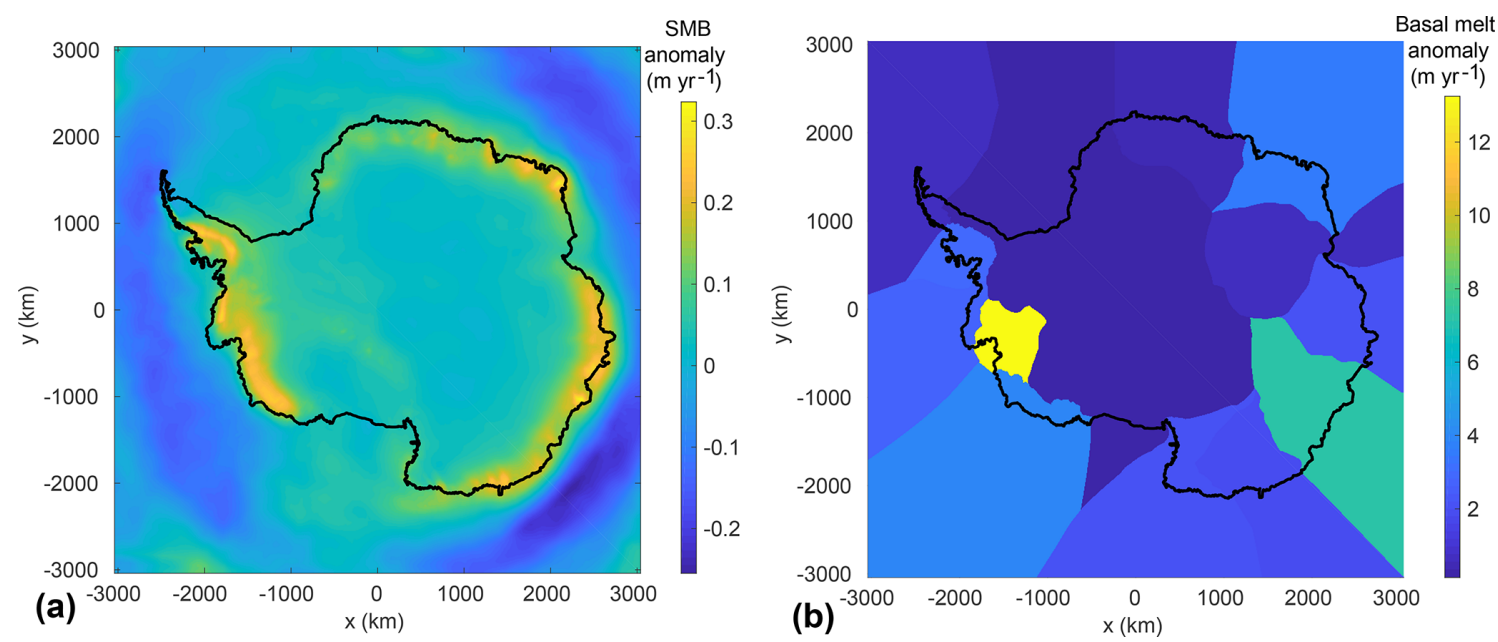

Figure 1. (a) Surface mass balance anomaly $\left(\mathrm{m} \mathrm{yr}^{-1}\right)$ for the asmb experiment and (b) basal melt rate anomaly (m yr $\left.{ }^{-1}\right)$ for the abmb experiment. Black contours show the current Antarctic ice extent.

described in Pollard and DeConto (2012a). Four models are based on a steady-state equilibrium in which the model is run for an extended period of time, until the ice sheet becomes close to a steady-state equilibrium, with two models also including present-day geometry as a target (Pollard and DeConto, 2012a). The remaining seven initializations are based on data assimilation, with three models also including a short relaxation period after the data assimilation to limit the impact of inconsistent datasets (Seroussi et al., 2011; GilletChaulet et al., 2012).

For the external SMB forcing, models use output from RACMO2 (Lenaerts et al., 2012), RACMO2.3 (van Wessem et al., 2014), RACMO2.3p2 (van Wessem et al., 2018), MAR (Agosta et al., 2019), ERA Interim (Dee et al., 2011), or Arthern et al. (2006). Five simulations use a positive degreeday scheme (PDD; Reeh, 1991). These choices generate relatively similar initial SMB (see Sect. 4). For sub-shelf melting, three simulations do not apply any melt rate. Four others apply values estimated from remote sensing, extrapolated to regions that unground during the simulation. Most models apply a parameterization that depends linearly (Martin et al., 2011; eight simulations) or quadratically (DeConto and Pollard, 2016; four simulations) on the ocean thermal forcing. Three simulations adjust the melt rate using an observed thickness target, and the remaining three simulations use the new Potsdam Ice-shelf Cavity model (PICO) parameterization (Reese et al., 2018).

Most models include a moving ice front, but five simulations have a fixed ice front. Ice front migration is primarily based on strain rate in most cases (Levermann et al., 2012; 10 simulations). Some models use ice flux divergence and accumulated damage at the ice front (Pollard et al., 2015; three simulations), and some have ice-front retreat based on a threshold ice thickness (four simulations), while the others have retreat only where the ice melts completely (three simulations).

\section{Results}

\section{1 init experiment}

Each model reports initial ice sheet conditions at the end of the initialization procedure (init). The total ice-covered area varies between $1.35 \times 10^{7}$ and $1.50 \times 10^{7} \mathrm{~km}^{2}$, a range of only $10.5 \%$ among models. The ice shelf extent, on the other hand, varies significantly among models, from $0.92 \times 10^{6}$ to $2.51 \times 10^{6} \mathrm{~km}^{2}$, a range of $6.4 \%$ to $16.7 \%$ of the total icecovered area. Figure 2 summarizes the initial extent of all models. Some models have ice shelves hundreds of kilometers upstream or downstream of their current observed location. Although models generally agree on the location of the three largest ice shelves (Ross, Ronne-Filchner, and Amery), the location and extent of smaller shelves vary widely, including in the Amundsen and Bellingshausen Sea sectors. The initial ice mass above floatation varies from $1.79 \times 10^{7}$ to $2.47 \times 10^{7} \mathrm{Gt}$ (between 49.4 and $68.1 \mathrm{~m}$ of SLE), while the total ice mass varies from $2.11 \times 10^{7}$ to $2.56 \times 10^{7} \mathrm{Gt}$, in part because of the large discrepancy in ice shelf extent. Table $\mathrm{C} 1$ details the main scalar variables in init for all simulations.

The ability of models to reproduce the characteristics of the present-day ice sheet depends on their initialization procedure. The root mean square error (RMSE) between observed (Fretwell et al., 2013) and modeled ice thickness varies between 91.2 and $422.3 \mathrm{~m}$, with generally smaller errors (between 91.2 and $320.8 \mathrm{~m}$ ) for models using data assimilation or present-day geometry as a target in their initialization and larger errors (between 160.0 and $422.3 \mathrm{~m}$ ) for models using spin-up, a steady state, or long relaxation procedures without a geometry target (Fig. 3a). The RMSE be- 
Table 1. List of participants, modeling groups, and ice flow models in ISMIP6 initMIP-Antarctica.

\begin{tabular}{|c|c|c|c|}
\hline Contributors & Group ID & Ice flow model & Group \\
\hline $\begin{array}{l}\text { Nicholas Golledge } \\
\text { Daniel Lowry }\end{array}$ & $\mathrm{ARC}$ & PISM & $\begin{array}{l}\text { Antarctic Research Centre, } \\
\text { Victoria University of Wellington, New Zealand }\end{array}$ \\
\hline $\begin{array}{l}\text { Thomas Kleiner } \\
\text { Johannes Sutter } \\
\text { Angelika Humbert }\end{array}$ & AWI & PISM & $\begin{array}{l}\text { Alfred Wegener Institute for Polar and Marine Research, } \\
\text { Bremerhaven, Germany }\end{array}$ \\
\hline Stephen Cornford & СРOM & BISICLES & Swansea University, UK \\
\hline Christian Rodehacke & DMI & PISM & Danish Meteorological Institute, Denmark \\
\hline $\begin{array}{l}\text { Matthew Hoffman } \\
\text { Tong Zhang } \\
\text { Stephen Price }\end{array}$ & DOE & MALI & Los Alamos National Laboratory, USA \\
\hline $\begin{array}{l}\text { Julien Brondex } \\
\text { Fabien Gillet-Chaulet }\end{array}$ & IGE & Elmer/Ice & Institut des Géosciences de l'Environnement, France \\
\hline Ralf Greve & ILTS & SICOPOLIS & $\begin{array}{l}\text { Institute of Low Temperature Science, } \\
\text { Hokkaido University, Sapporo, Japan }\end{array}$ \\
\hline $\begin{array}{l}\text { Heiko Goelzer } \\
\text { Thomas Reerink } \\
\text { Roderik van de Wal }\end{array}$ & IMAU & IMAUICE & $\begin{array}{l}\text { Institute for Marine and Atmospheric Research, } \\
\text { Utrecht, the Netherlands }\end{array}$ \\
\hline $\begin{array}{l}\text { Nicole Schlegel } \\
\text { Hélène Seroussi }\end{array}$ & JPL & ISSM & $\begin{array}{l}\text { Jet Propulsion Laboratory, California Institute of Technology, } \\
\text { Pasadena, USA }\end{array}$ \\
\hline $\begin{array}{l}\text { Christophe Dumas } \\
\text { Aurélien Quiquet }\end{array}$ & LSCE & Grisli & $\begin{array}{l}\text { Laboratoire des Sciences du Climat et de l'Environnement, } \\
\text { Université Paris-Saclay, France }\end{array}$ \\
\hline $\begin{array}{l}\text { Gunter Leguy } \\
\text { William Lipscomb }\end{array}$ & NCAR & CISM & National Center for Atmospheric Research, Boulder, CO, USA \\
\hline $\begin{array}{l}\text { Torsten Albrecht } \\
\text { Matthias Mengel } \\
\text { Ronja Reese } \\
\text { Ricarda Winkelmann }\end{array}$ & PIK & PISM & Potsdam Institute for Climate Impact Research, Germany \\
\hline David Pollard & PSU & PSU & $\begin{array}{l}\text { Earth and Environmental Systems Institute, Pennsylvania } \\
\text { State University, University Park, PA, USA }\end{array}$ \\
\hline $\begin{array}{l}\text { Mathieu Morlighem } \\
\text { Helene Seroussi }\end{array}$ & UCIJPL & ISSM & $\begin{array}{l}\text { University of California, Irvine, USA } \\
\text { Jet Propulsion Laboratory, California Institute of Technology, } \\
\text { Pasadena, USA }\end{array}$ \\
\hline $\begin{array}{l}\text { Frank Pattyn } \\
\text { Sainan Sun }\end{array}$ & ULB & f.ETISh & Université libre de Bruxelles, Belgium \\
\hline $\begin{array}{l}\text { Jonas Van Breedam } \\
\text { Philippe Huybrechts }\end{array}$ & VUB & AISMPALEO & Vrije Universiteit Brussel, Belgium \\
\hline
\end{tabular}

tween observed (Rignot et al., 2011a) and modeled surface velocity (Fig. 3b) also has a large spread among models, varying from 47.5 to $308 \mathrm{~m} \mathrm{yr}^{-1}$. These values are significantly affected by the inclusion of observed surface velocities during the initialization procedure: the RMSE in surface speed varies from 47.5 to $94.5 \mathrm{~m} \mathrm{yr}^{-1}$ for models including data assimilation of surface velocities and from 116 to $308 \mathrm{~m} \mathrm{yr}^{-1}$ for the other models. Most of these errors are caused by large discrepancies in ice shelves and a few fast-flowing ice streams: the RMSE for the logarithm of the speed, which emphasizes the slower-moving regions, varies only between 0.62 and 1.51 (Fig. 3c), or 3 times less than the RMSE of the speed. These errors are in part affected by the exact year of the initialization procedure, as observations of velocity and thickness are not acquired at the same time. However, the temporal variability of observed thickness and 
Table 2. List of initMIP-Antarctica simulations and main model characteristics. Numerics rely on the finite-difference (FD), finite-element (FE), or finite-volume (FV) method. Initialization methods are as follows: spin-up (SP), spin-up with target values for the ice thickness (SP+; see Pollard and DeConto, 2012a), data assimilation (DA), data assimilation with short relaxation (DA+), data assimilation of ice geometry (DA*), equilibrium state (Eq), and equilibrium state with target values for the ice thickness (Eq+). Initial SMB is derived from the following: RACMO2 (RA2; Lenaerts et al., 2012), RACMO2.3 (RA2.3; van Wessem et al., 2014), RACMO2.3p2 (RA2.3p2; van Wessem et al., 2018), MAR (Agosta et al., 2019), ERA Interim (ERA; Dee et al., 2011), Arthern et al. (2006) (Art), and positive degree-day schemes (PDD; Reeh, 1991). Basal melt rates are based on zero melting (0), linear function of thermal forcing (Lin; Martin et al., 2011), quadratic function of thermal forcing (Quad; DeConto and Pollard, 2016), melt rates estimated from observations (Obs; Rignot et al., 2013; Depoorter et al., 2013), ice shelf thickness target (SS), ice shelf thickness target with no refreezing (SS*), and the PICO parameterization (Reese et al., 2018). Models that have partially floating cells at the grounding line apply melting using a sub-grid scheme (Sub-grid), a floatation condition to assess if melt should be applied over the entire cell or not (Floating condition), or no melt at all (No) in their partially floating cells. Ice front migration schemes are primarily based on strain rate (StR; Levermann et al., 2012), retreat only (RO), fixed front (Fix), minimum thickness height (MH), and divergence and accumulated damage (Div; Pollard et al., 2015). The DMI_PISM1 and DMI_PISM0 differ by the basal melt applied under the floating ice, with a basal melt reduced by an order of magnitude in DMI_PISM1 compared to DMI_PISM0. Further details on all the models are given in Appendix B.

\begin{tabular}{|c|c|c|c|c|c|c|c|c|c|}
\hline Model name & Numerics & $\begin{array}{l}\text { Stress } \\
\text { balance }\end{array}$ & $\begin{array}{r}\begin{array}{r}\text { Resolution } \\
(\mathrm{km})\end{array}\end{array}$ & Initialization & $\begin{array}{r}\text { Initial } \\
\text { year }\end{array}$ & $\begin{array}{l}\text { Initial } \\
\text { SMB }\end{array}$ & $\begin{array}{l}\text { Initial } \\
\text { basal melt }\end{array}$ & $\begin{array}{l}\text { Melt in partially } \\
\text { floating cells }\end{array}$ & $\begin{array}{l}\text { Ice } \\
\text { front }\end{array}$ \\
\hline ARC_PISM1 & FD & Hybrid & 16 & SP & 2000 & RA2 & 0 & No & StR \\
\hline ARC_PISM2 & FD & Hybrid & 16 & SP & 2000 & RA2 & 0 & Sub-grid & StR \\
\hline ARC_PISMB & $\mathrm{FD}$ & Hybrid & 16 & SP & 2000 & RA2 & Lin & No & StR \\
\hline ARC_PISM4 & FD & Hybrid & 16 & SP & 2000 & RA2 & Lin & Sub-grid & StR \\
\hline AWI_PISM1Eq & $\mathrm{FD}$ & Hybrid & 16 & $\mathrm{Eq}$ & 1979-2011 & RA2.3 & Quad & No & StR \\
\hline AWI_PISM1Pal & $\mathrm{FD}$ & Hybrid & 16 & SP & 1979-2011 & RA2.3 & Quad & No & StR \\
\hline CPOM_BISICLES_A & FV & L1L2 & $0.5-8$ & $\mathrm{DA}+$ & 2010 & Art & SS & No & RO \\
\hline CPOM_BISICLES_B & FV & L1L2 & $0.5-8$ & $\mathrm{DA}+$ & 2010 & Art & SS & No & RO \\
\hline DMI_PISM0 & $\mathrm{FD}$ & Hybrid & 16 & SP & 1979-2012 & ERA & Lin & No & StR \\
\hline DMI_PISM1 & $\mathrm{FD}$ & Hybrid & 16 & SP & 1979-2012 & ERA & Lin & No & StR \\
\hline DOE_MALI & $\mathrm{FE} / \mathrm{FV}$ & $\mathrm{HO}$ & $2-20$ & $\mathrm{DA}+$ & 2007 & RA2 & Obs & $\begin{array}{l}\text { Floating } \\
\text { condition }\end{array}$ & Fix \\
\hline IGE_ELMER & $\mathrm{FE}$ & SSA & $1-50$ & $\mathrm{DA}+$ & 2000 & MAR & Lin & No & Fix \\
\hline IITS_SICOPOLIS1 & FD & SIA & 8 & SP & 1990 & PDD & Lin & $\mathrm{n} / \mathrm{a}$ & $\mathrm{MH}$ \\
\hline ILTS_SICOPOLIS2 & FD & Hybrid & 8 & SP & 1990 & PDD & Lin & $\mathrm{n} / \mathrm{a}$ & $\mathrm{MH}$ \\
\hline IMAU__IMAUICE 32 & $\mathrm{FD}$ & Hybrid & 32 & $\mathrm{Eq}$ & 1990 & RA2.3 & 0 & No & Fix \\
\hline JPL1_ISSM & $\mathrm{FE}$ & SSA & $1-50$ & $\mathrm{DA}$ & 2007 & RA2 & Obs & Sub-grid & Fix \\
\hline LSCE_GRISLI & $\mathrm{FD}$ & Hybrid & 16 & $\mathrm{SP}+$ & 2000 & MAR & SS & $\mathrm{n} / \mathrm{a}$ & $\mathrm{MH}$ \\
\hline NCAR_CISM & $\mathrm{FE} / \mathrm{FV}$ & L1L2 & 4 & $\mathrm{SP}+$ & 1979-2016 & RA $2.3 p 2$ & Obs & $\begin{array}{l}\text { Floating } \\
\text { condition }\end{array}$ & RO \\
\hline PIK_PISM3PAL & $\mathrm{FD}$ & Hybrid & 16 & $\mathrm{SP}+$ & $1986-2005$ & RA2.3 & $\mathrm{PICO}$ & Sub-grid & StR \\
\hline PIK_PISM4EQUI & $\mathrm{FD}$ & Hybrid & 8 & $\mathrm{Eq}+$ & $1986-2005$ & $\mathrm{RA} 2.3 \mathrm{p} 2$ & $\mathrm{PICO}$ & Sub-grid & StR \\
\hline PSU_EQNOMEC & $\mathrm{FD}$ & Hybrid & 16 & $\mathrm{Eq}^{+}$ & $1979-2010$ & PDD & Quad & Sub-grid & Div \\
\hline PSU_GLNOMEC & $\mathrm{FD}$ & Hybrid & 16 & $\mathrm{SP}+$ & $1979-2010$ & PDD & Quad & Sub-grid & Div \\
\hline UCIJPL_ISSM & $\mathrm{FE}$ & $\mathrm{HO}$ & $3-50$ & DA & 2007 & RA2 & Obs & Sub-grid & Fix \\
\hline ULB_FETISH1 & $\mathrm{FD}$ & Hybrid & 16 & $\mathrm{DA}^{*}$ & 1979-2014 & RA2.3 & $\mathrm{PICO}$ & $\mathrm{n} / \mathrm{a}$ & Div \\
\hline VUB_AISMPALEO & FD & $\mathrm{SIA}+\mathrm{SSA}$ & 20 & SP & 2000 & PDD & Lin & $\mathrm{n} / \mathrm{a}$ & $\mathrm{MH}$ \\
\hline
\end{tabular}

n/a: not applicable.

velocity is small compared to the discrepancies between observations and models, so the exact year used for the initial state has a limited impact on the RMSE calculated.

Area-integrated external forcings (SMB and basal melt) also differ substantially among the models (see Table $\mathrm{C} 1$ in the Appendix C). The total initial SMB varies from 2015 to $3430 \mathrm{Gt} \mathrm{yr}^{-1}$, depending on the origin of the SMB forcing (see Table 2) and the extent of the ice-covered areas. The total initial ocean-induced basal melt varies from 0 to $2470 \mathrm{Gt} \mathrm{yr}^{-1}$, with seven models having values of less than $150 \mathrm{Gt} \mathrm{yr}^{-1}$, while remote sensing estimates of total Antarctic basal melt are $\sim 1400 \mathrm{Gt} \mathrm{yr}^{-1}$ (Rignot et al., 2013; De- poorter et al., 2013). Similar to the SMB forcing, these differences result from the chosen melting parameterization ( $\mathrm{Ta}-$ ble 2) and the geometry of ice shelves.

\section{2 ctrl experiment}

Representing the current state of the ice sheet does not guarantee that the current trends in ice sheet changes are correctly captured, which is what eventually matters in sea level rise projections. In the ctrl experiment, the Antarctic ice sheet evolves under a constant climate for 100 years. The total change of ice mass above floatation varies from a loss of $60500 \mathrm{Gt}$ to a gain of $88100 \mathrm{Gt}$ (i.e., $243 \mathrm{~mm}$ of SLE drop 
Initial ice extent

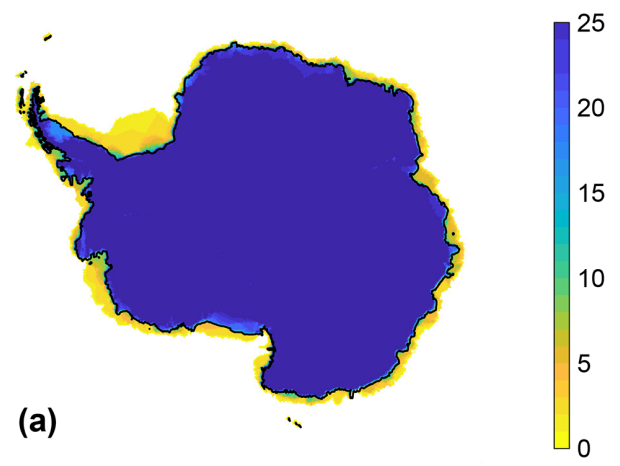

Initial ice shelf extent

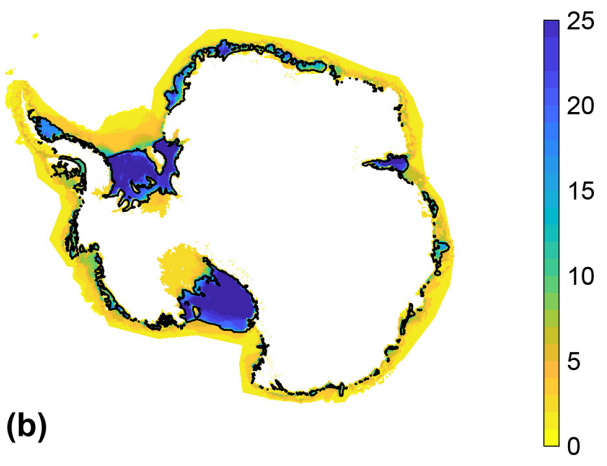

Figure 2. Initial extent of ice-covered areas and ice shelves for all participating models. All contributions are regridded onto an $8 \mathrm{~km}$ standard grid. Figures indicate how many models include ice $(\mathbf{a}, \mathbf{b})$ or floating ice (b) in each grid cell. Black lines show the observed ice extent $(\mathbf{a})$ and ice shelf extent (b) from Bedmap2 (Fretwell et al., 2013).
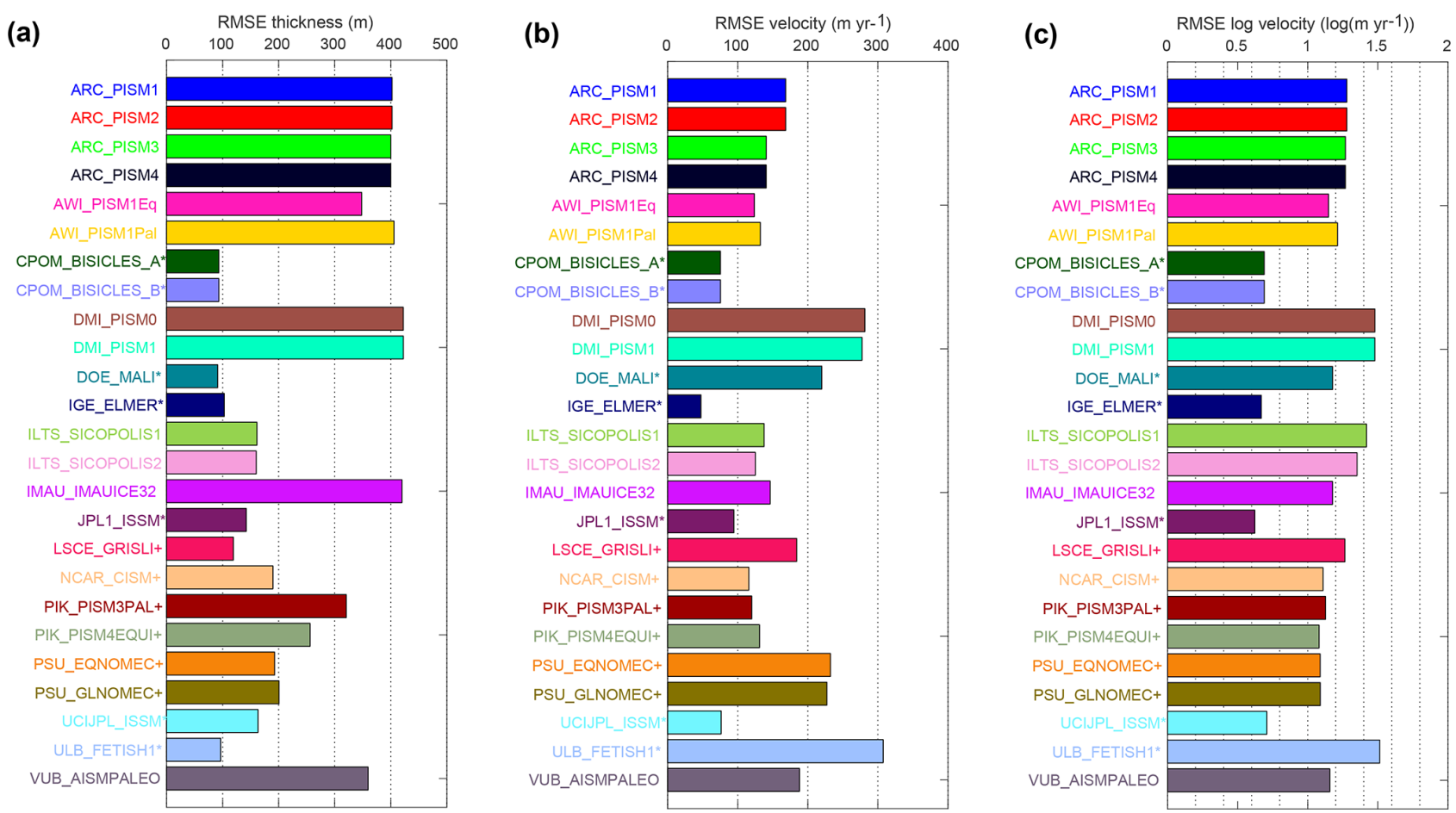

Figure 3. Root mean square error (RMSE) of modeled initial conditions compared to observations for (a) initial ice thickness (m), (b) initial ice surface velocity $\left(\mathrm{m} \mathrm{yr}^{-1}\right)$ over the ice sheet and ice shelf, and (c) the logarithm of the initial ice surface velocity $\left(\log \left(\mathrm{m} \mathrm{yr}^{-1}\right)\right)$. Please note that the model-color relationship used in this figure is applied in all subsequent figures. Models that assimilate present-day conditions during their initialization process are denoted with + if they integrate geometry and $*$ if they integrate velocity and geometry information.

to $167 \mathrm{~mm}$ of SLE rise; see Fig. 4a and Table B2), with mass loss in 8 simulations and gain in 17 simulations. This absolute change in mass above floatation represents less than $0.42 \%$ of the initial volume in all cases, highlighting the accuracy required to calculate the Antarctic evolution for sea level projections. A spread of results is observed for all initialization methods and model resolutions. Eleven models have an absolute change lower than $20 \mathrm{~mm}, 10$ have an absolute change above $80 \mathrm{~mm}$, and four have an absolute change between 20 and $80 \mathrm{~mm}$. All the models initialized with a steady-state equilibrium but one have a sea level change lower than $20 \mathrm{~mm}$, while all the models using data assimilation to determine their initial conditions but one have a sea level change above $80 \mathrm{~mm}$. The models based on a paleoclimate spin-up have a large spread of sea level change in the ctrl experiment and are present in all categories. The number 
of models in each category is, however, relatively small to draw definitive conclusions.

Figure 5 shows the spatial patterns of thickness and depthaverage horizontal ice speed for the ctrl experiment. Regridded results on the $8 \mathrm{~km}$ standard grid are used to compute modeled mean changes and standard deviation for these two variables. Results are reported only where at least five simulations have ice at a given grid point. Maps of thickness and velocity change during the ctrl experiment show that the signals are larger along the coast than in the interior of the continent and larger in West Antarctica compared to East Antarctica. The ice sheet mean thickness change, averaged over all models, is equal to $1.2 \mathrm{~m}$ in 100 years. The standard deviation is calculated for each grid cell of the $8 \mathrm{~km}$ standard grid based on the number of models reporting results in each cell and excluding cells where fewer than five models simulate ice. The standard deviation is much larger than the mean changes in many places, with an average value over the simulated area of $14.8 \mathrm{~m}$. Substantial thickening and thinning (especially of ice shelves) compensate for each other, leading to a small spatial average change but large standard deviation. Similarly, the spatial average velocity change is small, with a value of $-1.9 \mathrm{~m} \mathrm{yr}^{-1}$, but the standard deviation is $27.4 \mathrm{~m} \mathrm{yr}^{-1}$. Some models have large accelerations in key regions, while others have large slowdowns. Regions with the largest spread in model thickness and velocity changes are generally similar.

The ice extent is relatively temporally stable in all ctrl simulations, with less than $1.3 \%$ change in the most sensitive simulations. Some simulations, however, have large temporal changes in ice shelf extent, ranging from a reduction of $13 \%$ to an increase of $14 \%$. The area-integrated SMB varies by up to $6 \%$ for the simulations that experience the largest change in SMB (Fig. 6b). The area-integrated basal melting varies by more than $5 \%$ for 15 models, with a maximum change of $29 \%$, in response to changes in ice shelf extent and thickness (Fig. 6c).

\section{3 asmb experiment}

In the asmb experiment, an SMB anomaly (Fig. 1a) is added to the SMB used in the ctrl experiment. This anomaly leads to an increase in ice mass above floatation compared to ctrl, with the mass gain ranging from $4.51 \times 10^{4}$ to $6.72 \times 10^{4} \mathrm{Gt}$ (125-186 mm decrease in SLE; see Fig. 4b). The differences among models (Fig. 7a, b) are linked to the extent of the icecovered areas, as well as ice shelf extent. For most models there is a small increase in grounded area, as some floating areas near grounding lines thicken and reground due to the positive SMB anomaly.

Figure 8 shows the mean and standard deviation of the impact of this SMB anomaly on the ice thickness and depthaveraged horizontal velocity. Figure 8 is similar to Fig. 5 but for the difference between the end of the asmb experiment and the end of the ctrl experiment. As expected from the
SMB anomaly spatial pattern (Fig. 1a), there is a thickening of $3.6 \mathrm{~m}$ on average over Antarctica, with the largest changes happening along the West Antarctic coasts and the Antarctic Peninsula (Fig. 8a). The standard deviation map (Fig. 8c) shows that model differences are again concentrated along the West Antarctica coast and on the Antarctic Peninsula. The average standard deviation over the continent is $5.2 \mathrm{~m}$ for this anomaly. The SMB anomaly has a small impact on ice dynamics, as shown in Fig. 8b, with a spatial average speed increase of $1.5 \mathrm{~m} \mathrm{yr}^{-1}$ over 100 years and a standard deviation of $17.6 \mathrm{~m} \mathrm{yr}^{-1}$. Regions where models disagree are similar to those for the ctrl experiment. Figure 9a compares for each model the difference in mass between the end of the asmb experiment and the end of the ctrl experiment with the cumulative SMB anomaly of the asmb experiment integrated over the entire ice sheet. It confirms that the additional SMB is the primary cause of mass change: the SMB anomaly explains between $97 \%$ and $130 \%$ of the total mass change. The difference between the cumulative SMB anomaly and the change in mass is caused by thicker and faster ice (see Fig. 8) that increases the calving flux, as well as feedbacks on ice shelf basal melt.

\section{4 abmb experiment}

In the abmb experiment, an anomaly is applied to the basal melting rate of floating ice shelves, in addition to the basal melting used in the ctrl experiment. The basal melt anomaly is uniform within each region (see Fig. 1b) and largest in the Amundsen Sea, where an additional ocean-induced melt of $13.2 \mathrm{~m} \mathrm{yr}^{-1}$ is applied. This additional melting leads to a thinning of ice shelves, a reduction of the buttressing they provide to grounded ice, an acceleration of the ice streams feeding the shelves, and a retreat of grounding lines. However, unlike what is observed for the asmb experiment, the abmb response varies significantly among models.

Differences can be attributed in part to different treatments of basal melt in model cells near the grounding line. Some models have no melting in partially floating cells, others apply melt in partially floating cells based on the fraction of floating area, and two models apply melt over the entire cell if it satisfies a floatation criterion (see Table 2). The spread in ice mass loss above floatation compared to the end of the ctrl experiment varies by 2 orders of magnitude, from $4.7 \times 10^{3}$ to $1.5 \times 10^{5} \mathrm{Gt}$ (or $13-427 \mathrm{~mm}$ of SLE; see Fig. $4 \mathrm{c}$ and Table B2 in Appendix B), even though the additional melt is applied only to floating ice and therefore does not contribute directly to sea level rise. The grounded area is reduced for all the models (between $0.10 \%$ and $1.7 \%$ reduction) as grounding lines retreat. The change in ice shelf extent varies from a reduction of $25 \%$ to an increase of $12 \%$, as some ice shelves calve during this experiment, depending on the choice made for ice front evolution (see Table 2).

Figure 10 shows that the modeled mean and standard deviation for the ice thickness and depth-averaged velocity 

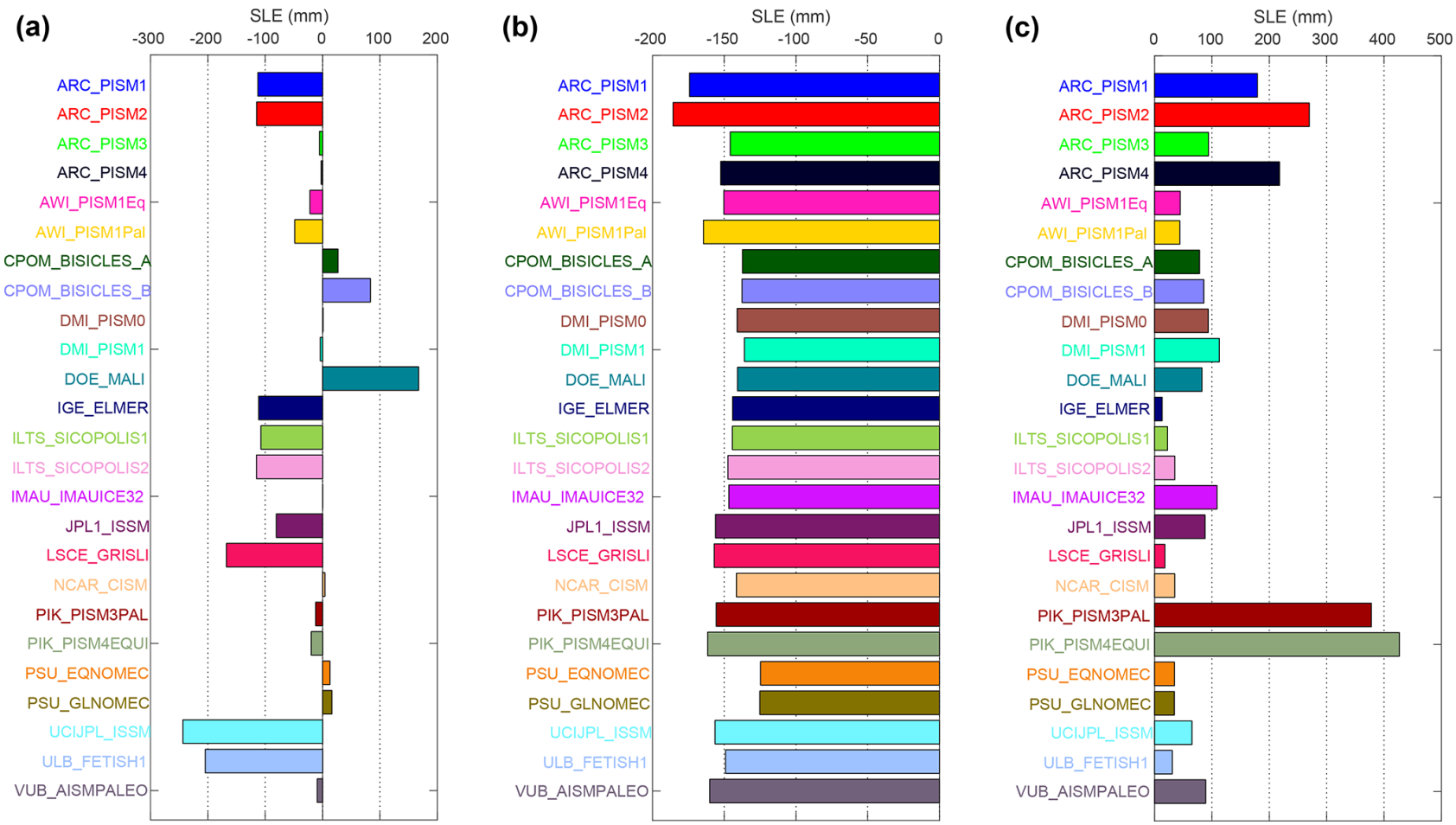

Figure 4. Antarctic contribution to sea level ( $\mathrm{mm}$ of sea level equivalent). (a) ctrl experiment, (b) difference between asmb and ctrl experiments, and (c) difference between abmb and ctrl experiments. Negative values of SLE represent a growing ice sheet.

changes are concentrated on the ice shelves and near grounding lines. Ice thinning is $10.7 \mathrm{~m}$ on average, and the standard deviation is $12.4 \mathrm{~m}$. The dynamic impact of such variations is not limited to the ice shelves but propagates upstream of the grounding line, especially in the Amundsen Sea Basin, where the largest anomalies are applied. The Ross and FilchnerRonne ice shelves have acceleration near the grounding line but also a slowdown near the ice front. The modeled mean velocity change over the ice sheet is a small slowdown of $3.3 \mathrm{~m} \mathrm{yr}^{-1}$; this signal is small compared to the standard deviation of $29.6 \mathrm{~m} \mathrm{yr}^{-1}$. Regions where models show a large spread of thickness and velocity changes are different from the ctrl and asmb simulations. Large deviations among models extend upstream from the present-day grounding lines and over the ice streams feeding the ice shelves, reflecting different model responses to this oceanic forcing. Figure $9 b$ compares for each model the difference in mass between the end of the abmb experiment and the end of the ctrl experiment, with the cumulative basal melt anomaly of the abmb experiment integrated over the entire ice sheet. It shows that the additional basal melt only accounts for a fraction of the mass change: the basal melt anomaly explains between $5 \%$ and $125 \%$ of the total mass change. The difference between the cumulative basal melt anomaly and the change in mass is mainly caused by thinner and slower ice shelves (see Fig. 10) that reduce the calving flux.

\section{Discussion}

The initMIP-Antarctica experiments are designed to analyze the impact of ice sheet model initial conditions on the evolution of the Antarctic ice sheet and its response to simple climate forcings. For this exercise, 16 groups submitted $25 \mathrm{sim}-$ ulations, more than 4 times the number of Antarctic simulations submitted for the SeaRISE project (Bindschadler et al., 2013), highlighting the importance and the fast evolution of this research field (Pattyn et al., 2017). The simulations represent a large diversity of initialization methods, forcing datasets, and model parameters, and the results show a large spread in the mass balance and dynamic evolution of this ice sheet in century-scale simulations.

The initial ice volume above floatation varies from 1.8 to $2.5 \times 10^{7} \mathrm{Gt}$, or almost $32 \%$, which is much larger than the spread of about $8 \%$ in SeaRISE (Nowicki et al., 2013b). This is not surprising given the larger number of model contributions. On the other hand, the largest drifts in the ctrl experiment are reduced compared to the SeaRISE project. For initMIP-Antarctica, the ctrl sea level contribution varies between -243 and $+167 \mathrm{~mm}$ of sea level equivalent for the 25 simulations of ISMIP6, while its evolution varied between -256 and $+1 \mathrm{~mm}$ over the first 100 years for the six simulations of SeaRISE. Specifically, four models participated in both SeaRISE and initMIP-Antarctica, and the large drift that 
Mean thickness change ctrl

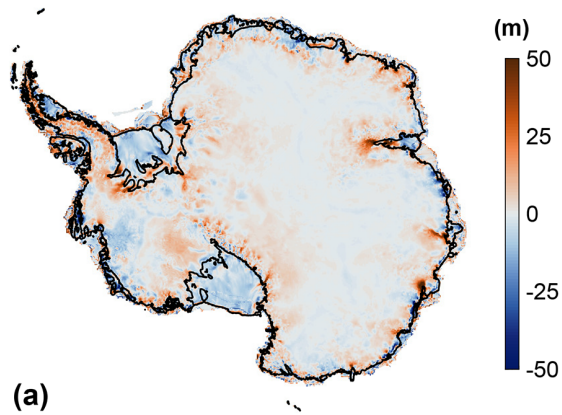

Standard deviation thickness change ctrl

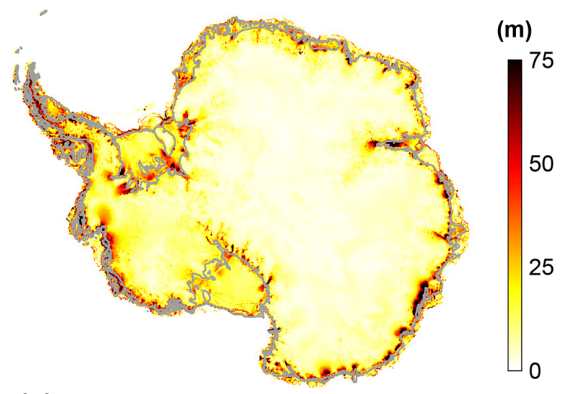

(c)
Mean velocity change ctrl

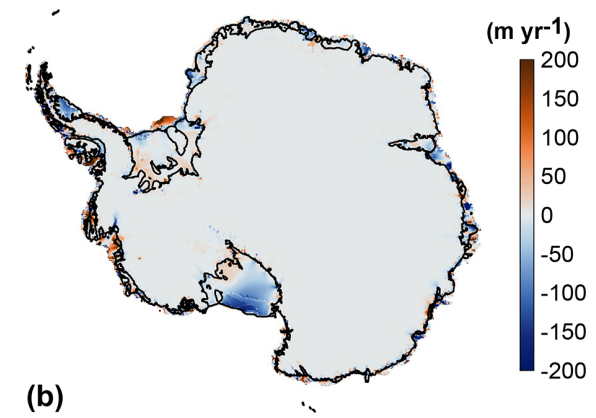

Standard deviation velocity change ctrl

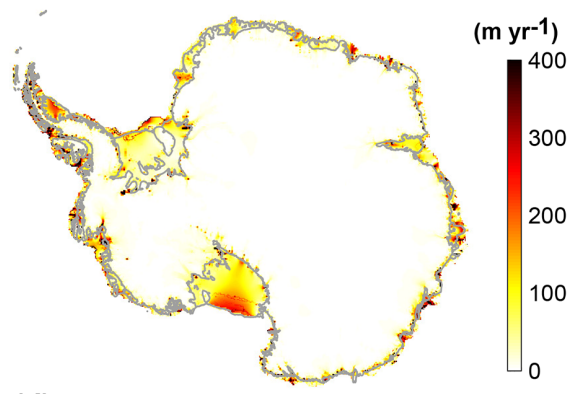

(d)

Figure 5. Mean $(\mathbf{a}, \mathbf{b})$ and standard deviation $(\mathbf{c}, \mathbf{d})$ of the change in ice thickness (a and $\mathbf{c}$, in $\mathrm{m})$ and depth-averaged horizontal velocity $(\mathbf{b}$ and $\mathbf{d}$, in $\mathrm{m} \mathrm{yr}^{-1}$ ) between the beginning and end of the ctrl experiment. Black (a, c) or grey $(\mathbf{b}, \mathbf{d})$ lines show the observed current ice front and grounding line positions.
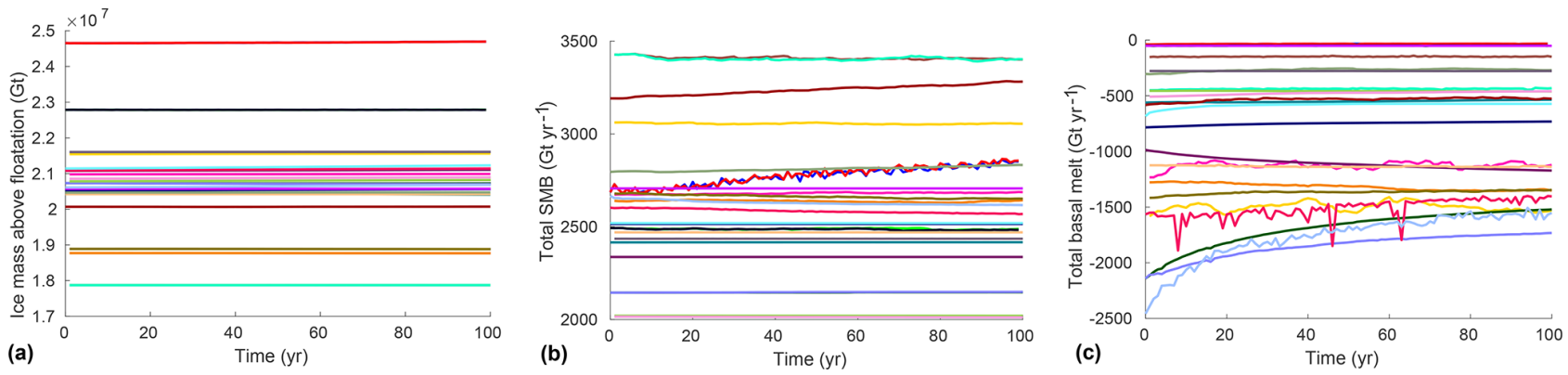

Figure 6. Evolution of Antarctic ice sheet mass above floatation and external forcings in the ctrl experiment. (a) Total mass of ice above floatation (Gt), (b) total SMB applied at the ice surface $\left(\mathrm{Gt} \mathrm{yr}^{-1}\right)$, and (c) total basal melting rate $\left(\mathrm{Gt}^{-1} \mathrm{r}^{-1}\right)$.

two of them experienced in SeaRISE has been reduced in the initMIP-Antarctica ctrl experiment.

The asmb and abmb experiments are designed to analyze the ice sheet response to simple anomalies in SMB and basal melting under the ice shelves. Unlike initMIP-Greenland, where Goelzer et al. (2018) observed a large spread of $118 \%$ in the responses in the asmb experiment, the response to the SMB anomaly in initMIP-Antarctica is similar among all the models, with a $39 \%$ variation in the response to this anomaly between the models. The differences can be attributed to the larger spread in initial ice sheet extent and the pattern of the
SMB anomaly in initMIP-Greenland. In Greenland, large ablation rates are applied at the ice sheet periphery, leading to significant ice loss for the models with the largest initial extents (Goelzer et al., 2018). The Antarctic SMB anomaly has less spatial variability, and the initial extent of the ice sheet is closer for the different simulations, which leads to more consistent responses to this perturbation.

While the response to the SMB anomaly has limited variations among models, the impact of the basal melting anomaly varies significantly among models, with a spread in sea level contribution from $13 \mathrm{~mm}$ to more than $400 \mathrm{~mm}$. Several fac- 

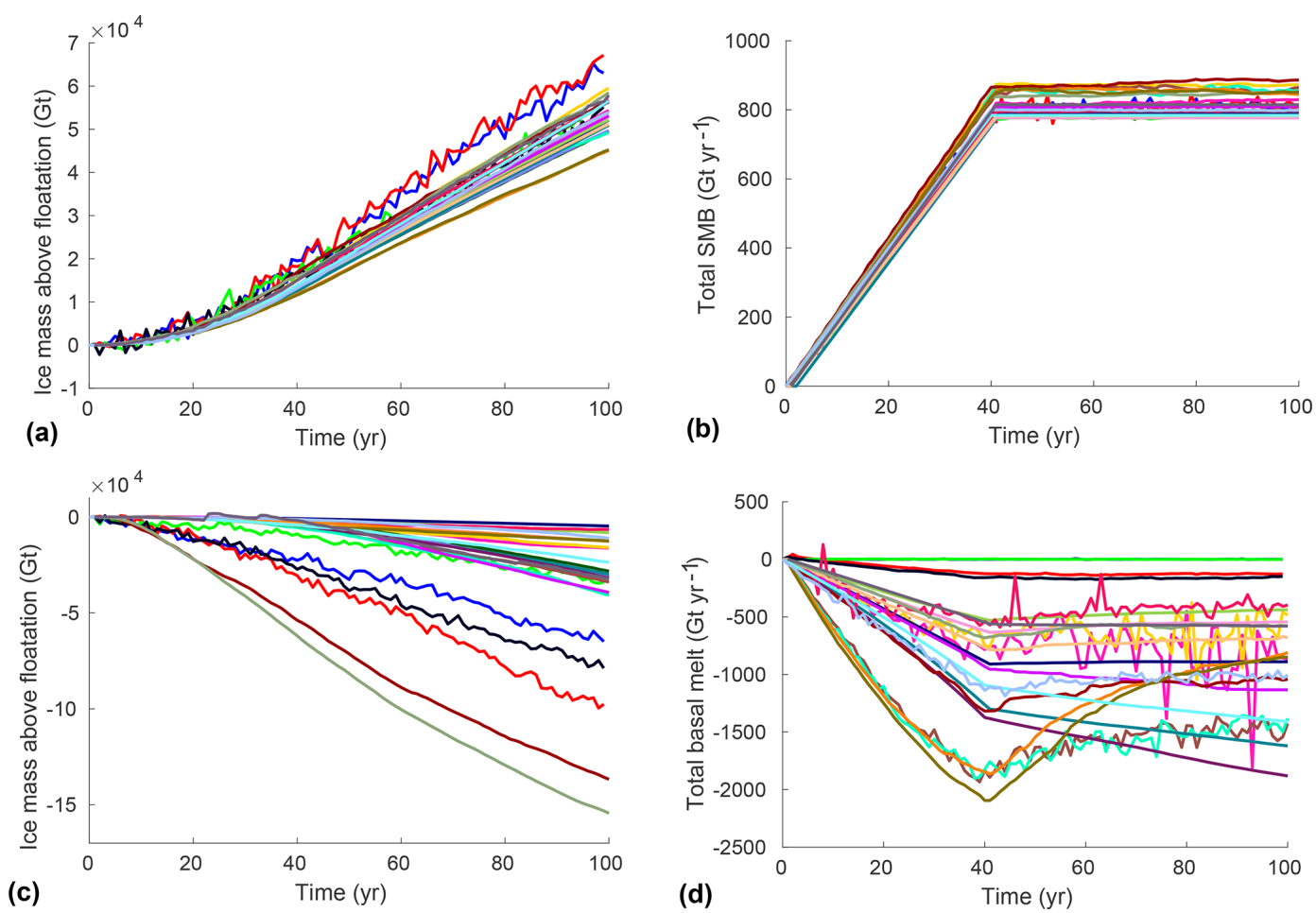

Figure 7. Evolution of the Antarctic ice sheet and external forcings in the asmb (a and $\mathbf{b}$ ) and abmb (c and $\mathbf{d}$ ) experiments compared to the ctrl experiment. Total amount of ice above floatation for asmb minus ctrl (a) and abmb minus ctrl (c) (in Gt). Evolution of SMB applied at

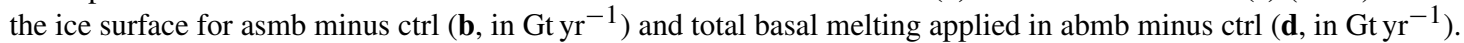

tors explain the wide range of abmb responses. First, models vary in their treatment of basal melting near the grounding line. Elements and grid cells crossed by the grounding line are considered partially floating. Some models have no melting in partially floating cells, others apply melt in partially floating cells based on the fraction of floating area, and two models apply melt over the entire cell if it satisfies a floatation criterion (see Table 2). These different treatments can have a significant impact on grounding line evolution, as highlighted by previous studies (Arthern and Williams, 2017; Seroussi and Morlighem, 2018). This is especially important for continental-scale simulations that have a resolution varying between several kilometers and several tens of kilometers, as is the case in initMIP-Antarctica. The four largest sea level contributions in the abmb experiment $(>200 \mathrm{~mm})$ come from four models that apply sub-grid melt in partially floating cells and have a resolution of $8 \mathrm{~km}$ or coarser (see Tables 2 and B2). Additionally, two of these models were run without (ARC_PISM1 and ARC_PISM3) and with (ARC_PISM2 and ARC_PISM4) a sub-grid melt scheme in partially floating cells (see Table 2), which resulted in an additional sea level rise of 90 and $124 \mathrm{~mm}$ when the sub-grid melt scheme was used.

Second, the total ice shelf extent varies by more than $100 \%$ among the different models, and their extent within different basins also varies significantly (see Fig. 2 and Ta- ble B1). As the basal melting anomaly is applied only under floating ice, the spatial extent and amount of the applied anomaly therefore vary significantly from one model to the next. Ice shelf extent also varies during the ctrl and abmb experiments, so that the applied melt anomaly evolves differently between the simulations. As shown in Fig. 11, floating ice areas stay relatively constant in some models, increase because of grounding line retreat in others, and decrease as ice shelves thin significantly and calve in the remaining ones.

Third, while the SMB applied in init and ctrl is relatively similar among the different models, the basal melting varies from zero melt to $2140 \mathrm{Gt} \mathrm{yr}^{-1}$. The latter value is about $50 \%$ larger than values derived from remote sensing observations (Rignot et al., 2013; Depoorter et al., 2013) (see Fig. 7). The applied basal melting anomaly therefore represents about half the initial basal melting for some models but a drastic increase for others. The impact on ice shelf thickness evolution and dynamic response is therefore very different, as shown by Fig. 10.

Finally, surface-elevation feedback processes were not allowed in asmb, ensuring that a similar SMB anomaly was applied by all models at a given location. In abmb, no such constraint was prescribed, which introduces feedbacks between ice shelf and basal melting for some parameterizations. For example, if an ice shelf thins and the grounding line retreats in a given model, the newly floating ice experiences basal 

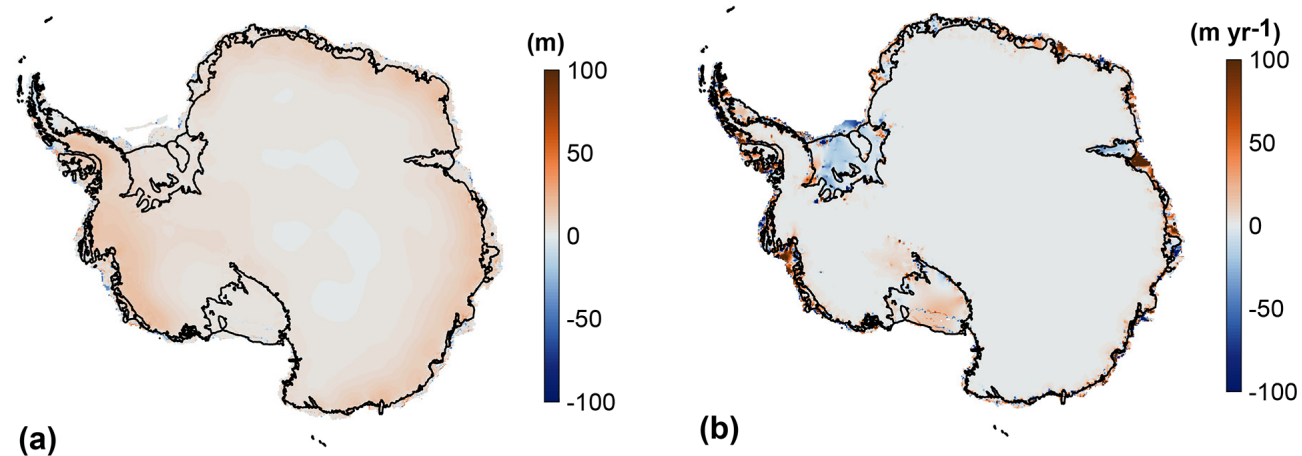

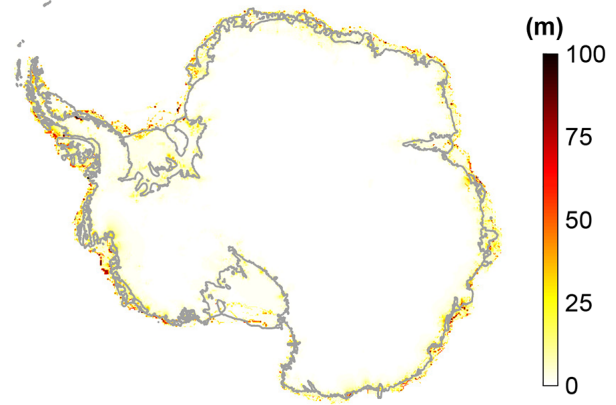

(c)

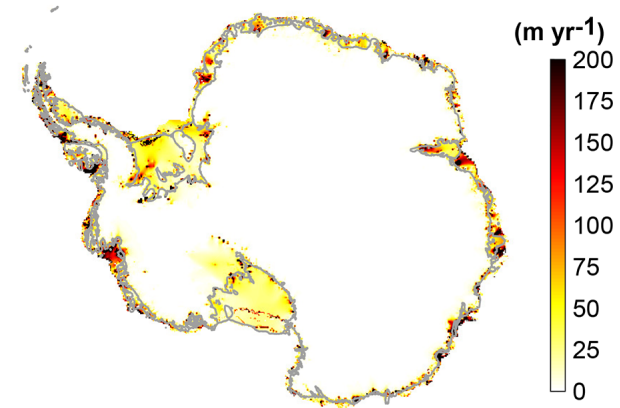

(d)

Figure 8. Mean (a, b) and standard deviation (c, d) of the ice thickness (a and $\mathbf{c}$, in $\mathrm{m}$ ) and depth-averaged horizontal velocity (b and $\mathbf{d}$, in $\mathrm{m} \mathrm{yr}^{-1}$ ) between the end of the asmb experiment and the end of the ctrl experiment. Black (a, b) or grey (c, d) lines show the current observed ice front and grounding line positions.
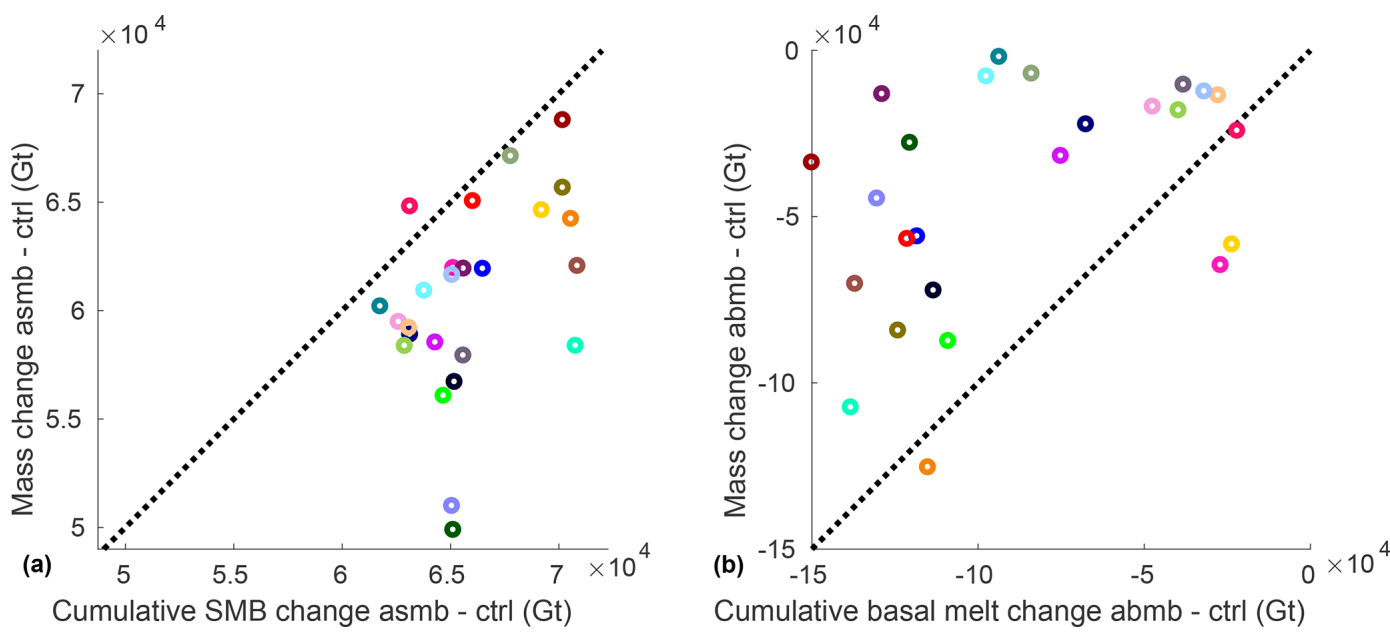

Figure 9. (a) Difference in mass (Gt) between the end of the asmb experiment and the end of the ctrl experiment and the cumulative SMB anomaly (Gt) of the asmb experiment integrated over the entire ice sheet for the 25 simulations. (b) Difference in mass (Gt) between the end of the abmb experiment and the end of the ctrl experiment and the cumulative basal melt anomaly (Gt) of the abmb experiment integrated over the entire ice sheet for the 25 simulations. Black dashed lines show mass change equal to cumulative anomaly change. 
Mean thickness change abmb - ctrl

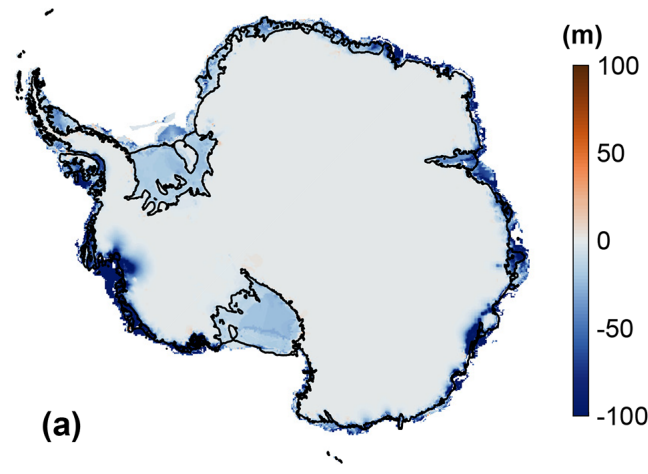

Standard deviation thickness change abmb - ctrl
Mean velocity change abmb - ctrl

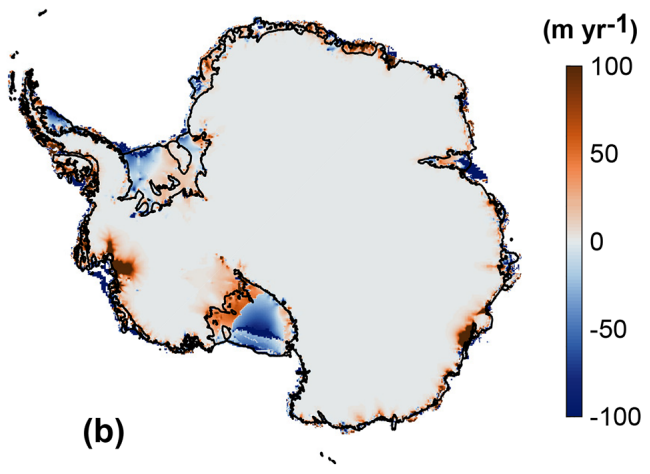

Standard deviation velocity change abmb - ctrl
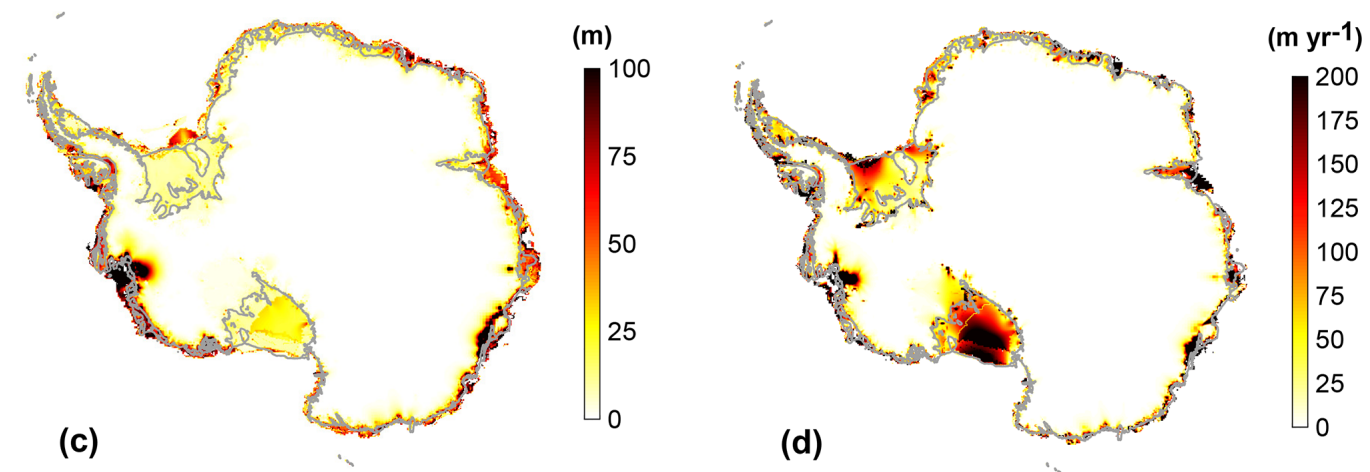

Figure 10. Mean $(\mathbf{a}, \mathbf{b})$ and standard deviation $(\mathbf{c}, \mathbf{d})$ of the change in ice thickness (a and $\mathbf{c}$, in $\mathrm{m})$ and depth-averaged horizontal velocity (b and $\mathbf{d}$, in $\mathrm{m} \mathrm{yr}^{-1}$ ) between the end of the abmb experiment and the end of the ctrl experiment. Black (a, b) or grey (c, d) lines show the current observed ice front and grounding line positions.

melting that can drive further thinning and retreat. The effective basal melting anomaly therefore varies between the simulations (see Fig. 7d). These results highlight the need for further modeling studies and observations on basal melting patterns near the grounding line.

One objective of ISMIP6 and initMIP-Antarctica is to gather a large and diverse ice sheet modeling community. To facilitate participation of a large number of models, only two constraints were imposed: (1) the inclusion of both grounded and floating ice and (2) the simulation of dynamic grounding line migration. This lack of constraints complicates the analysis of the simulation differences, since model parameters, input forcing, initialization techniques, and physical processes vary widely among models. Initialization methods that are based on the assimilation of present-day conditions usually have lower RMSE in the initial ice thickness and velocity compared to observations (Fig. 3) but larger trends in the ctrl experiment (Fig. 4a), while the opposite is true for models relying on paleoclimate spin-up or a steady-state solution. This is similar to what was previously observed by Nowicki et al. (2013a, b) and Goelzer et al. (2018). As the two approaches are complementary, models are start- ing to combine them by either following data assimilation with short relaxation periods or by assimilating surface elevation during transient initialization to have an initial geometry more consistent with observations (Pollard and DeConto, 2012a). Combining the best of both approaches is an active field of research. Assimilating observations over longer time periods looks like a promising option, despite the technical challenges (Larour et al., 2014; Goldberg et al., 2015).

Representation of ice shelves and their connection to glaciers upstream is an outstanding cause of differences among models. Ice shelves are directly affected by variations in oceanic (Jacobs et al., 2011; Pritchard et al., 2012; Greenbaum et al., 2015; Wouters et al., 2015) and atmospheric (Scambos et al., 2000; Banwell et al., 2013; Munneke et al., 2014; Bassis and Ma, 2015) conditions, which impacts grounding line and ice front evolution (Favier et al., 2014; Joughin et al., 2014; Rignot et al., 2014; Bassis and Ma, 2015; Scheuchl et al., 2016; Christie et al., 2016; Seroussi et al., 2017). Ice shelf evolution over the past few decades has been complex, with large spatial and temporal variability (Depoorter et al., 2013; Rignot et al., 2013; Paolo et al., 2015; Christie et al., 2018) that is not fully understood and 

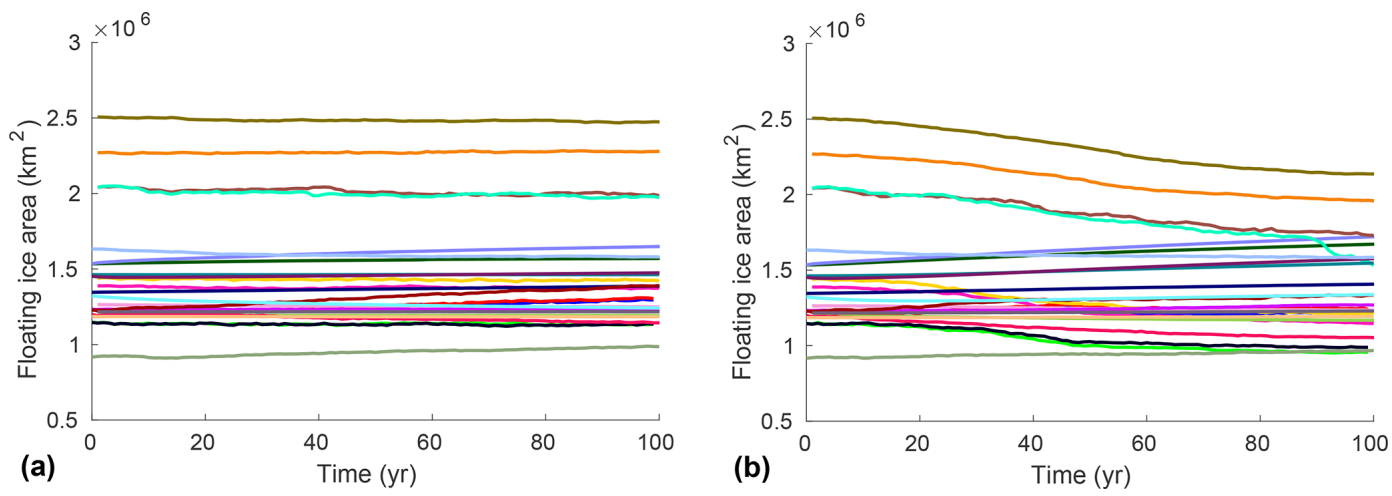

Figure 11. Evolution of Antarctic ice shelf extent for the (a) ctrl and (b) abmb experiments.

typically is not included in numerical models. Representation of ice shelves varies among models: the ice shelf extent, spatial location, and thickness differ significantly between the simulations, resulting in large deviations in ice shelf flow. Another major source of disagreement is the boundary condition at the ice-ocean interface, with ocean-induced basal melting applied under the floating ice and its temporal evolution based on a wide range of parameterizations. Significant progress was made over the past decade (Pattyn et al., 2017), but continued improvement of ice shelf representation in continental-scale models should remain a research priority so that ice shelf representation in continental-scale ice sheet models is in better agreement with observations of the current state of the Antarctic ice sheet.

The results presented in this study rely on simple atmospheric and oceanic forcings that are only loosely based on RCP scenarios. Furthermore, many participating models did not use their full capabilities. To reduce model differences, for example, participants were asked to turn off surfaceelevation feedback schemes, bedrock adjustment capabilities, and ice cliff failure. As a result, the initMIP-Antarctica simulations are not projections of Antarctic evolution over the coming century and should not be compared with previous Antarctic simulations aiming to simulate this evolution (e.g., Ritz et al., 2015; Golledge et al., 2015). The next step of ISMIP6 will be the assessment of Antarctic evolution under different scenarios forced with oceanic and atmospheric conditions derived from CMIP climate models; experiments are now being designed. The initMIP-Antarctic simulations do, however, illustrate the spread in ice sheet evolution (hence sea level) that is due to ice sheet model initial state and modeling choices (e.g., grounding line numerics, calving laws) and provide insight into uncertainty in simulations of sea level change.

\section{Conclusions}

The initMIP-Antarctica experiment, part of the Ice Sheet Model Intercomparison Project for CMIP6 (ISMIP6), had broad participation, with 25 model simulations submitted from 16 groups. Results are improved compared to previous similar exercises of continental-scale modeling of the Antarctic ice sheet, with enhanced representation of presentday conditions and ice mass loss trend. A first experiment performed with a simple surface mass balance anomaly forcing produces relatively robust results across the models, while a second experiment with a simple perturbation in basal melting rate under the ice shelves creates very large discrepancies in the ice sheet response. Variations in the representation of ice shelves (e.g., spatial extent, thickness), ice shelf basal melting, and numerical treatment of grounding lines cause this significant spread of results between the simulations. Including accurate representations of ice shelves that are consistent with observations of the current Antarctic ice sheet in continental-scale models should therefore remain an important research subject in the coming years. All the experiments performed as part of initMIP-Antarctica are based on simplified anomaly forcings. Future projections of the Antarctic ice sheet evolution under different climate scenarios are currently being designed and will be the subject of future ISMIP6 modeling experiments.

Data availability. The model output from the simulations described in this paper and forcing data sets will be made publicly available with a digital object identifier https://doi.org/10.5281/ zenodo.2651652. In order to document CMIP6's scientific impact and enable ongoing support of CMIP, users are asked to acknowledge CMIP6, ISMIP6, and the participating modeling groups. 


\section{Appendix A: Outputs and output format}

initMIP-Antarctica participants are required to provide output variables according to the data request plan. Three types of 2-D fields are reported by modeling groups at 5-year intervals: state variables, flux variables, and constants. Also, scalar outputs (e.g., total ice mass, ice mass above floatation, SMB, basal melt) are reported every simulation year. Table A1 provides the complete list of requested variables. In addition to model output results, a README file describing model characteristics and details of the initialization procedure was requested from modeling groups for each simulation.

Table A1. Data requests for initMIP-Antarctica. ST: state variable. FX: flux variable. CST: constant.

\begin{tabular}{|c|c|c|c|}
\hline Variable name & Type & Standard name & Unit \\
\hline Ice sheet thickness & ST & land_ice_thickness & $\mathrm{m}$ \\
\hline Ice sheet surface elevation & ST & surface_altitude & $\mathrm{m}$ \\
\hline Ice sheet base elevation & ST & base_altitude & $\mathrm{m}$ \\
\hline Bedrock elevation & ST & bedrock_altitude & $\mathrm{m}$ \\
\hline Geothermal heat flux & CST & upward_geothermal_heat_flux_at_ground_level & $\mathrm{W} \mathrm{m}^{-2}$ \\
\hline Surface mass balance flux & FL & land_ice_surface_specific_mass_balance_flux & $\mathrm{kg} \mathrm{m}^{-2} \mathrm{~s}^{-1}$ \\
\hline Basal mass balance flux & FL & land_ice_basal_specific_mass_balance_flux & $\mathrm{kg} \mathrm{m}^{-2} \mathrm{~s}^{-1}$ \\
\hline Ice thickness imbalance & FL & tendency_of_land_ice_thickness & $\mathrm{ms}^{-1}$ \\
\hline Surface velocity in $x$ direction & ST & land_ice_surface_x_velocity & $\mathrm{m} \mathrm{s}^{-1}$ \\
\hline Surface velocity in $y$ direction & ST & land_ice_surface_y_velocity & $\mathrm{m} \mathrm{s}^{-1}$ \\
\hline Surface velocity in $z$ direction & ST & land_ice_surface_upward_velocity & $\mathrm{ms}^{-1}$ \\
\hline Basal velocity in $x$ direction & ST & land_ice_basal_x_velocity & $\mathrm{m} \mathrm{s}^{-1}$ \\
\hline Basal velocity in $y$ direction & $\mathrm{ST}$ & land_ice_basal_y_velocity & $\mathrm{m} \mathrm{s}^{-1}$ \\
\hline Basal velocity in $z$ direction & $\mathrm{ST}$ & land_ice_basal_upward_velocity & $\mathrm{m} \mathrm{s}^{-1}$ \\
\hline Mean velocity in $x$ direction & ST & land_ice_vertical_mean_x_velocity & $\mathrm{ms}^{-1}$ \\
\hline Mean velocity in $y$ direction & ST & land_ice_vertical_mean_y_velocity & $\mathrm{m} \mathrm{s}^{-1}$ \\
\hline Ice surface temperature & ST & temperature_at_ground_level_in_snow_or_firn & $\mathrm{K}$ \\
\hline Ice basal temperature & ST & land_ice_basal_temperature & $\mathrm{K}$ \\
\hline Magnitude of basal drag & ST & magnitude_of_land_ice_basal_drag & $\mathrm{Pa}$ \\
\hline Land ice calving flux & FL & land_ice_specific_mass_flux_due_to_calving & $\mathrm{kg} \mathrm{m}^{-2} \mathrm{~s}^{-1}$ \\
\hline Grounding line flux & FL & land_ice_specific_mass_flux_due_at_grounding_line & $\mathrm{kg} \mathrm{m}^{-2} \mathrm{~s}^{-1}$ \\
\hline Land ice area fraction & ST & land_ice_area_fraction & 1 \\
\hline Grounded ice sheet area fraction & ST & grounded_ice_sheet_area_fraction & 1 \\
\hline Floating ice sheet area fraction & ST & floating_ice_sheet_area_fraction & 1 \\
\hline Total ice sheet mass & ST & land_ice_mass & $\mathrm{kg}$ \\
\hline Total ice sheet mass above floatation & ST & land_ice_mass_not_displacing_sea_water & $\mathrm{kg}$ \\
\hline Area covered by grounded ice & ST & grounded_land_ice_area & $\mathrm{m}^{2}$ \\
\hline Area covered by floating ice & ST & floating_ice_shelf_area & $\mathrm{m}^{2}$ \\
\hline Total SMB flux & FL & tendency_of_land_ice_mass_due_to_surface_mass_balance & $\mathrm{kg} \mathrm{s}^{-1}$ \\
\hline Total BMB flux & FL & tendency_of_land_ice_mass_due_to_basal_mass_balance & $\mathrm{kg} \mathrm{s}^{-1}$ \\
\hline Total calving flux & FL & tendency_of_land_ice_mass_due_to_calving & $\mathrm{kg} \mathrm{s}^{-1}$ \\
\hline Total grounding line flux & FL & tendency_of_grounded_ice_mass & $\mathrm{kg} \mathrm{s}^{-1}$ \\
\hline
\end{tabular}




\section{Appendix B: Model description and initialization}

Below are descriptions of the ice flow models and the initialization procedure performed by the different groups.

\section{B1 ARC_PISM}

We use the Parallel Ice Sheet Model (PISM) version 0.7.1. PISM is a hybrid ice sheet-ice shelf model that combines shallow approximations of the flow equations that compute gravitational flow and flow by horizontal stretching (Bueler and Brown, 2009). We perform two sets of experiments with different initialization procedures. In the first set (PISM-1,2), the simulations are initialized from the end of a 120000 -year spin-up using paleoclimate forcing, whereas in the second set (PISM-3,4), the simulations are initialized from the end of a 100 000-year spin-up using a constant climate forcing. Both procedures result in a present-day ice sheet configuration that is in a thermally and dynamically evolved state, with a "present-day" sea-level equivalent volume of 58.35 and $56.38 \mathrm{~m}$, respectively. The combined stress balance of PISM allows for a treatment of ice sheet flow that is consistent across non-sliding grounded ice to rapidly sliding grounded ice (ice streams) and floating ice (shelves). As with most continental-scale ice sheet models, we use flow enhancement factors for the shallow-ice and shallow-shelf components of the stress regime (3.5 and 0.5, respectively, for PISM-1,2, and 2.8 and 0.5 , respectively, for PISM-3,4), which allow us to adjust creep and sliding velocities using simple coefficients. By doing so we are able to optimize simulations such that modeled behavior is consistent with observed behavior. The junction between grounded and floating ice is refined by a sub-grid-scale parameterization (Feldmann et al., 2014) that smooths the basal shear stress field and tracks an interpolated grounding-line position through time. This allows for much more realistic grounding-line motion, even with relatively coarse spatial grids, such as the $16 \mathrm{~km}$ grid used in our experiments. We run duplicate experiments with the subgrid melt turned off (PISM-1,3) or on (PISM-2,4) in order to quantify the effect of this scheme. SMB is calculated using a positive degree-day model that takes as inputs air temperature and precipitation from RACMO2.1 (Lenaerts et al., 2012). In previous simulations (e.g., Golledge et al., 2015) we have derived evolving melt beneath ice shelves from the thermodynamic three-equation model of Hellmer and Olber (1989), in which the melt rate is primarily controlled by salinity and temperature gradients across the ice-ocean interface. For the simplified experiments presented here, however, we set a spatially uniform melt rate as an initial condition and allow our modeled ice sheet to evolve in response to this.

\section{B2 AWI_PISM}

The simulations are performed with PISM version 0.7.3. For the 220 ka-long spin-up simulations with paleoclimatic forcing (PISM1Pal), time slice anomalies for the Last Interglacial (LIG) and the Last Glacial Maximum (LGM) from the Earth System Model COSMOS (Pfeiffer and Lohmann, 2016; Zhang et al., 2014) are used in addition to datasets for present-day (PD) Antarctic climate (RACMO2.3, van Wessem et al., 2014; WOA09, Locarnini et al., 2010). Timedependent and spatially variable climate anomaly fields are interpolated during the PISM run between LIG, LGM, and PD climate time slices with a glacial index method (Sutter et al., 2016), where the glacial index is derived from Dome C deuterium depletion (Jouzel et al., 2007). For the SMB, PISM's positive degree-day (PDD) scheme is used. Relative sea level forcing (Waelbroeck et al., 2002) and bed deformation (Bueler et al., 2007) are applied during the paleo spin-up. In addition to the paleo spin-up, a $100 \mathrm{ka}-\mathrm{long}$ equilibrium-type spin-up (PISM1Eq) with steady presentday climate (ocean and atmosphere) and sea level is carried out with isostatic bed deformation. Instead of precipitation and $2 \mathrm{~m}$ air temperature (PISM1Pal), SMB and skin temperature from RACMO2.3 are directly applied without the PDD scheme. The initial geometry for both spin-ups is Bedmap2 (Fretwell et al., 2013), and the geothermal flux is from Shapiro and Ritzwoller (2004). Basal shelf melt rates are calculated via a quadratic form of the melt rate formula in Beckmann and Goosse (2003) using the extrapolated 3-D ocean temperatures at the depth of the ice shelf base. PISM's sub-grid grounding line scheme for basal sliding (Feldmann et al., 2014) is used in all simulations.

\section{B3 CPOM_BISICLES}

CPOM_BISICLES_A_500m is a block structured adaptive mesh finite-element model based on a vertically integrated stress balance model (Cornford et al., 2013, 2016) and the basal friction physics of Tsai et al. (2015). Here, we make use of the adaptive mesh to maintain a resolution of $8 \mathrm{~km}$ in the slow-moving interior, $1 \mathrm{~km}$ in ice streams, and $500 \mathrm{~m}$ at the grounding line. The initial state is based on ice thickness and bedrock elevation from Bedmap2 (Fretwell et al., 2013), modified according to mass conservation close to the grounding line to avoid the large unphysical thickening rates that would otherwise occur, especially in the Amundsen Sea Embayment. Ice temperature is taken from Pattyn (2010) and is held constant in time over the course of the simulations. Effective viscosity $\varphi(x, y)$ and effective drag coefficients $\beta^{2}(x, y)$ are estimated by minimizing the mismatch between modeled speed the observed speed of Rignot et al. (2011b), following the methods described in Cornford et al. (2015) The background ocean melt rate $M_{0}(x, y, t)$ is defined so that the thinning rate is zero across the ice shelf and varies in time accordingly, so that when a melt rate anomaly $M_{a}(x, y, t)$ is applied, the ice shelf thinning rate is $M_{a}(x, y, t)$.

CPOM_BISICLES_B is similar to CPOM_BISICLES_A but does not allow accumulation onto the lower surface of the 
ice shelf, so that the ice sheet thins where $\operatorname{div}(\mathrm{uh})>0$, even with no anomaly.

\section{B4 DMI PISM}

The Parallel Ice Sheet Model (PISM; version 0.7) used utilizes a hybrid system (Bueler and Brown, 2009) combining the Shallow Ice Approximation (SIA) and Shallow Shelf Approximation (SSA) on a polar stereographic grid of $16 \mathrm{~km}$. Monthly atmospheric forcing is deduced from sub-daily ERA-Interim reanalysis products (Berrisford et al., 2011; Dee et al., 2011) covering the period 1979-2012. Its $2 \mathrm{~m}$ air temperature drives the ice surface temperature, while the total precipitation is considered as snow accumulation due to negligible surface melting in Antarctica. Starting from the contemporary ice sheet geometry, both ice internal enthalpy and temperature evolve for 150000 years for a fixed ice geometry due to surface and geothermal heat fluxes. Afterward the model runs freely for 25000 years, so that the model updates grounded ice margins, grounding lines, and calving fronts continuously. The calving parametrization exploits three sub-schemes for grid points at the ice shelf margins: the eigencalving parameterization (Levermann et al., 2012), which utilizes the stress field divergence with the proportionality constant of $5 \times 10^{17}$, the ice shelf margin with a thickness of less than $150 \mathrm{~m}$ calve, and ice shelves that extend into the depth ocean calve. Assuming a constant ocean temperature of $-1.7^{\circ} \mathrm{C}$ and melting factor $\left(F_{\text {melt }}=0.001\right)$, sub-shelf melting follows Eq. (5) in Martin et al. (2011) and occurs only for fully floating grid points, while the grounding line position is determined on a sub-grid space (Feldmann et al., 2014). The basal resistance is described as plastic till for which the yield stress is given by a Mohr-Coulomb formula (Bueler and Brown, 2009; Schoof, 2006). In DMI_PISM1 the basal melting rate of ice shelves is increased by an order of magnitude compared to DMI_PISM0.

\section{B5 DOE_MALI}

MPAS-Albany Land Ice (MALI) (Hoffman et al., 2018) uses a three-dimensional, first-order Blatter-Pattyn momentum balance solver solved using finite-element methods. Ice velocity is solved on a two-dimensional map plane triangulation extruded vertically to form tetrahedra. Mass and tracer transport occurs on the Voronoi dual mesh using a massconserving finite-volume first-order upwind scheme. Mesh resolution is $2 \mathrm{~km}$ along grounding lines and in all marine regions of West Antarctica and in marine regions of East Antarctica where present-day ice thickness is less than $2500 \mathrm{~m}$ to ensure that the grounding line remains in the fineresolution region, even under full retreat of West Antarctica and large parts of East Antarctica. Mesh resolution coarsens to $20 \mathrm{~km}$ in the ice sheet interior and no greater than $6 \mathrm{~km}$ in the large ice shelves. The horizontal mesh has 1.6 million cells. The mesh uses 10 vertical layers that are finest near the bed (4\% of total thickness) and coarsen towards the surface ( $23 \%$ of total thickness). Ice temperature is based on results from Van Liefferinge and Pattyn (2013) and held fixed in time. The model uses a linear basal friction law with spatially varying basal friction coefficient. The basal friction of grounded ice and the viscosity of floating ice are inferred to best match observed surface velocity (Rignot et al., 2011b) using an adjoint-based optimization method (Perego et al., 2014) and then kept constant in time. The grounding line position is determined using hydrostatic equilibrium, with sub-element parameterization of the friction. Sub-ice-shelf melt rates come from Rignot et al. (2013) and are extrapolated across the entire model domain to provide non-zero ice shelf melt rates after grounding line retreat. The SMB is from RACMO2.1 1979-2010 mean (Lenaerts et al., 2012). Maps of SMB and basal mass balance forcing are kept constant with time. The ice front position is fixed at the extent of the present-day ice sheet. After initialization, the model is relaxed for 99 years, so that the geometry and grounding lines can adjust.

\section{B6 IGE_Elmer-Ice}

For the momentum equations, we solve the Shelfy-Stream Approximation. Using the methodology presented in Fürst et al. $(2015,2016)$, we rely on inverse methods to initialize the model to present-day conditions. We use the presentday ice sheet topography and assimilate observed horizontal surface velocities to tune the basal friction coefficient and ice viscosity. The cost function also includes the mismatch between flux divergence and SMB and basal mass balance. The initial friction coefficient and viscosity fields are kept constant during the forward simulations. The model is relaxed with a constant forcing for 20 years after the initialization. For the control experiment the SMB comes from the regional atmospheric model MAR (Agosta et al., 2019) and is an averaged SMB between 1979 and 2015. The basal melt rate depends on the difference between ocean temperature and ocean freezing point and is a parameterization by sector based on Pollard and DeConto (2012a). The bedrock topography is taken from Bedmap2 (Fretwell et al., 2013), except that we include two pinning points in contact with the bottom surface of Thwaites ice shelf using the bathymetry of Millan et al. (2017). The mesh is fixed, and the resolution has been adapted to equidistribute the interpolation error of the observed velocities and thickness with an additional criterion based on grounding line proximity. The horizontal resolution ranges between $1 \mathrm{~km}$ and $50 \mathrm{~km}$. 


\section{B7 ILTS_SICOPOLIS}

We use SICOPOLIS version 3.3-dev with either shallowice dynamics (ILTS_SICOPOLIS1) or hybrid shallow-iceshelfy-stream dynamics (ILTS_SICOPOLIS2; Bernales et al., 2017) for grounded ice and shallow-shelf dynamics for floating ice. Ice thermodynamics is treated with the meltingCTS enthalpy method (ENTM) by Greve and Blatter (2016). The ice surface is assumed to be traction-free. Basal sliding under grounded ice is described by a Weertman-type sliding law, with sub-melt sliding in the form of Sato and Greve (2012). The model is initialized by a paleoclimatic spin-up over 140000 years, forced by Vostok $\delta D$ converted to $\Delta T$ (Petit et al., 1999), in which the topography is nudged towards the present-day topography to enforce a good agreement. In the future climate simulations, the ice topography evolves freely. For the last 2000 years of the spin-up and the future climate simulations, a regular (structured) grid with $8 \mathrm{~km}$ resolution is used. In the vertical, we use terrainfollowing coordinates with 81 layers in the ice domain and 41 layers in the thermal lithosphere layer below. The presentday surface temperature is parameterized (Fortuin and Oerlemans, 1990), the present-day precipitation is by Arthern et al. (2006) and Le Brocq et al. (2010), runoff is modeled by the positive degree-day method with the parameters by Sato and Greve (2012), the bed topography is Bedmap2 (Fretwell et al., 2013), and the geothermal heat flux is by Purucker (2012). Present-day ice shelf basal melting is parameterized as a function of both the depth of ice below mean sea level and ocean temperatures outside the ice shelf fronts at $500 \mathrm{~m}$ depth, tuned differently for eight Antarctic sectors (Greve and Galton-Fenzi, 2017).

\section{B8 IMAU_IMAUICE}

The finite-difference model (de Boer et al., 2014) uses a combination of SIA and SSA solutions, with velocities added over grounded ice to model basal sliding (Bueler and Brown, 2009). The model grid at $32 \mathrm{~km}$ horizontal resolution covers the entire Antarctic ice sheet and surrounding ice shelves. The grounded ice margin is freely evolving, while the shelf extends to the grid margin, and a calving front is not explicitly determined. We use the Schoof flux boundary condition (Schoof, 2007) at the grounding line with a heuristic rule following Pollard and DeConto (2012b). For the initMIP experiments, the sea level equation is not solved or coupled (de Boer et al., 2014). We run the thermodynamically coupled model with constant present-day boundary conditions to determine a thermodynamic steady state. The model is first initialized for $100 \mathrm{kyr}$ using the average 1979-2014 SMB and surface ice temperature from RACMO2.3 (van Wessem et al., 2014) and mapped with OBLIMAP (Reerink et al., 2010, 2016). Bedrock elevation is fixed in time with data taken from the Bedmap2 dataset (Fretwell et al., 2013), and geothermal heat flux data are from Shapiro and Ritz- woller (2004) and mapped with OBLIMAP (Reerink et al., 2010, 2016). We then run for $30 \mathrm{kyr}$ with constant ice temperature from the first run to get to a dynamic steady state, which is our initial condition.

\section{B9 JPL_ISSM}

Model setup, as follows, is adapted from Schlegel et al. (2018). The model domain covers the present-day Antarctic ice sheet, and its geometry is interpolated from the Bedmap2 dataset (Fretwell et al., 2013), with additional refinement in the Amundsen Sea sector, Recovery Ice Stream, and Totten Glacier, from Morlighem et al. (2011) and Rignot et al. (2014). The forward simulations rely on a 2-D ShelfyStream Approximation (MacAyeal, 1989) for stress balance, with a mesh resolution varying between $1 \mathrm{~km}$ at the domain boundary and within the shear margins and $50 \mathrm{~km}$ in the interior and a resolution of $8 \mathrm{~km}$ or finer within the boundary of all initial ice shelves. To estimate land ice viscosity, we compute the ice temperature based on a thermal steady state with 15 vertical layers (Seroussi et al., 2013), using threedimensional higher-order (Blatter, 1995; Pattyn, 2003) stress balance equations, observations of surface velocities (Rignot et al., 2011b), and basal friction inferred from surface elevations (Morlighem et al., 2010). Thermal boundary conditions are geothermal heat flux from Maule et al. (2005) and surface temperatures from Lenaerts et al. (2012). Steady-state ice temperatures are vertically averaged, used as inputs in the ice flow law, and held constant over time. To infer the unknown basal friction coefficient over grounded ice and the ice viscosity of the floating ice, we use data assimilation (MacAyeal, 1993; Morlighem et al., 2010) to reproduce observed surface velocities from Rignot et al. (2011b). Then, we run the model forward for 2 years, allowing the grounding line position and ice geometry to relax (Seroussi et al., 2011; Gillet-Chaulet et al., 2012). The grounding line evolves assuming hydrostatic equilibrium and following a sub-element grid scheme (SEP2 in Seroussi et al., 2014). The ice front remains fixed in time during all simulations performed, and we impose a minimum ice thickness of $1 \mathrm{~m}$ everywhere in the domain. The SMB and the ice shelf basal melt rates used in the control experiment are respectively from the 19792010 mean of RACMO2.1 (Lenaerts et al., 2012) and from the 2004-2013 mean from Schodlok et al. (2016).

\section{B10 LSCE_GRISLI}

The GRISLI model is a three-dimensional thermomechanically coupled ice sheet model originating from the coupling of the inland ice model of Ritz (1992) and Ritz et al. (1997) and the ice shelf model of Rommelaere (1996), extended to the case of ice streams treated as dragging ice shelves (Ritz et al., 2001). In the version used here, over the whole domain, the velocity field consists in the superposition of the ShallowIce Approximation (SIA) velocities for ice flow due to verti- 
cal shearing and the shallow-shelf approximation (SSA) velocities, used as a sliding law (Bueler and Brown, 2009). For the initMIP-Antarctica experiments, we used the GRISLI version 2.0 (Quiquet et al., 2018) which includes the analytical formulation of Schoof (2007) to compute the flux at the grounding line. Basal drag is computed with a power-law basal friction (Weertman, 1957). For this study, we use an iterative inversion method to infer a spatially variable basal drag coefficient that insures an ice thickness as close as possible to observations with a minimal model drift (Le clec'h et al., 2018). The basal drag is assumed to be constant for the forward experiments.

The model uses finite differences on a staggered Arakawa $\mathrm{C}$-grid in the horizontal plane at $16 \mathrm{~km}$ resolution with 21 vertical levels. Atmospheric forcing, namely near-surface air temperature and SMB, is taken from the 1979-2014 climatological annual mean computed by the MAR version 3.6.4 regional atmospheric model (Agosta et al., 2019). Initial subshelf basal melting rates are the regionally averaged basal melting rates that ensure a minimal ice shelf thickness Eulerian derivative in a forward experiment with constant climate and fixed grounding line position. The initial ice sheet geometry, bedrock and ice thickness, is taken from the Bedmap2 dataset (Fretwell et al., 2013), and the geothermal heat flux is from Shapiro and Ritzwoller (2004).

\section{B11 NCAR_CISM}

The Community Ice Sheet Model (CISM; Lipscomb et al., 2019) uses finite-element methods to solve a depthintegrated higher-order approximation (Goldberg, 2011) over the entire Antarctic ice sheet. The model uses a structured rectangular grid with uniform horizontal resolution of $4 \mathrm{~km}$ and five vertical $\sigma$ coordinate levels. The ice sheet is initialized with present-day geometry and an idealized temperature profile, then spun up for 30000 years using 19792016 climatological SMB and surface air temperature from RACMO2.3p2 (van Wessem et al., 2018; Lenaerts et al., 2012). During the spin-up, basal friction parameters (for grounded ice) and sub-shelf melt rates (for floating ice) are adjusted to nudge the ice surface elevation toward presentday observations. This method is a hybrid approach between assimilation and spin-up, similar to that described by Pollard and DeConto (2012a). The geothermal heat flux is taken from Le Brocq et al. (2010). The basal sliding is similar to that of Schoof (2005), combining power-law and Coulomb behavior. The grounding line location is determined using hydrostatic equilibrium and sub-element parameterization (Gladstone et al., 2010; Leguy et al., 2014). Basal melt is applied in grid cells that satisfy a floatation condition based on cell thickness and bed elevation; this includes some but not all cells intersected by the grounding line. The calving front is initialized from present-day observations and thereafter is allowed to retreat but not advance. See Lipscomb et al. (2019) for more information about the model.

\section{B12 PIK_PISM}

With the Parallel Ice Sheet Model (PISM; Winkelmann et al., 2011; http://www.pism-docs.org; version 9ae1674 from 2 August 2017), we performed a paleoclimatic spin-up and an equilibrium simulation on a regular rectangular grid with 16 and $8 \mathrm{~km}$ horizontal resolution, respectively. The vertical resolution increases from $130 \mathrm{~m}$ at the top of the domain to $20 \mathrm{~m}$ at the (ice) base, with a domain height of $6000 \mathrm{~m}$. PISM uses a hybrid of the Shallow-Ice Approximation (SIA) and the two-dimensional Shelfy-Stream Approximation of the stress balance (SSA; MacAyeal, 1989; Bueler and Brown, 2009) over the entire Antarctic ice sheet. The grounding line position is determined using hydrostatic equilibrium, with sub-grid interpolation of the friction at the grounding line (Feldmann et al., 2014). The calving front position can freely evolve using the eigencalving parameterization (Levermann et al., 2012). PISM is a thermomechanically coupled (polythermal) model based on the Glen-PatersonBudd-Lliboutry-Duval flow law (Aschwanden et al., 2012). The three-dimensional enthalpy field can evolve freely for given boundary conditions.

The model is initialized from Bedmap2 geometry (Fretwell et al., 2013), with precipitation from RACMOv2.3 1986-2005 mean (van Wessem et al., 2014) remapped from $27 \mathrm{~km}$ resolution and a parameterized ice surface temperature using the positive degree-day scheme (PDD; Huybrechts and de Wolde, 1999, modified by Martin et al., 2011) for PIK_PISM3PAL. In contrast, PIK_PISM4EQUI uses SMB and temperature directly from RACMOv2.3p2 (van Wessem et al., 2018) without PDD. The geothermal heat flux is from Shapiro and Ritzwoller (2004). We use the Potsdam Ice-shelf Cavity model (PICO; Reese et al., 2018) to calculate basal melt rate patterns underneath the ice shelves. We use observed ocean temperature and salinity mean values over the period 1975-2012 (Schmidtko et al., 2014) to drive PICO. The Mohr-Coulomb criterion relates the yield stress by parameterizations of till material properties to the effective pressure on the saturated till (Bueler and van Pelt, 2015). Till friction angle is a shear strength parameter for the till material property and is optimized iteratively in the grounded-ice region such that the mismatch of equilibrium and modern surface elevation is minimized. This is analogous to the friction-coefficient optimization in Pollard and DeConto (2012a).

\section{B13 PSU_PSUICE}

The Penn State University 3-D ice sheet model (PSUICE3D) is described in Pollard and DeConto (2012b), with updates in Pollard et al. (2015). The dynamics use a hybrid combination of vertically averaged SIA and SSA scaling. Floating ice shelves and grounding-line migration are included, with sub-grid interpolation for grounding-line position. The Schoof (2007) boundary-layer formulation is im- 
posed as a condition on ice velocity across the grounding line. The model includes standard equations for the evolution of ice thickness and internal ice temperatures with 10 unevenly spaced vertical layers. Bedrock deformation under the ice load is modeled as an elastic lithospheric plate above local isostatic relaxation (ELRA). Basal sliding follows a Weertman-type power law, occurring only where the bed is close to the melt point. Basal sliding coefficients are determined using an inverse method (Pollard and DeConto, 2012a), iteratively matching ice surface elevations to modern observations. Atmospheric temperatures and precipitation are obtained from the ALBMAP climatology (Le Brocq et al., 2010), with an imposed sinusoidal cycle for monthly air temperatures, interpolated to the ice sheet grid for SMB calculations. Oceanic melting at the base of ice shelves depends on the squared difference between nearby $400 \mathrm{~m}$ depth climatological ocean temperature (Levitus, 2012) and the melt point at the bottom of the ice. "Standard" calving of ice shelves is included. InitMIP experiments are run without recently proposed mechanisms of hydrofracturing by surface meltwater and structural failure of large ice cliffs (Pollard et al., 2015; DeConto and Pollard, 2016). The model grid size is $16 \mathrm{~km}$, and two types of initialization are used: (i) spun up to modern equilibrium (for $60 \mathrm{kyr}$ ) with constant invariant model climate forcing and (ii) run from 40 ka to modern time using paleoclimate forcing, and the model state at the end of that run is used.

\section{B14 UCIJPL_ISSM}

We rely on inverse modeling to initialize the model to present-day conditions, following Morlighem et al. (2013). The mesh horizontal resolution varies from $3 \mathrm{~km}$ along the coast (in the vicinity of grounding lines and in shear margins) to $30 \mathrm{~km}$ inland and is extruded vertically in 10 layers. We use a higher-order stress balance (Pattyn, 2003) and an enthalpy-based thermal model (Aschwanden et al., 2012; Seroussi et al., 2013). We first perform an inversion of ice shelf viscosity and then an inversion of basal drag under grounded ice, assuming a thermomechanical steady state. Our geometry is primarily based on Bedmap-2 (Fretwell et al., 2013), with local improvements based on mass conservation in the Amundsen Sea Embayment, along the coast of Wilkes Land, and on Recovery Ice Stream (Morlighem et al., 2011; Millan et al., 2017). The thermal model is constrained by surface temperatures from Comiso (2000) and the geothermal heat flux from Shapiro and Ritzwoller (2004), both included in the SeaRISE dataset (Nowicki et al., 2013b). The SMB used in the control experiment is from RACMO2.3 (van Wessem et al., 2014).

\section{B15 ULB_f.ETISh}

The f.ETISh (fast Elementary Thermomechanical Ice Sheet) model (Pattyn, 2017) version 1.3 is a vertically integrated hybrid finite-difference (SSA for basal sliding; SIA for grounded ice deformation) ice sheet/ice shelf model with vertically integrated thermomechanical coupling. The transient englacial temperature field is calculated in a 3-D fashion. The marine boundary is represented by a grounding-line flux condition according to Schoof (2007), coherent with power-law basal sliding (power-law coefficient of 2). Model initialization is based on an adapted iterative procedure based on Pollard and DeConto (2012a) to fit the model as close as possible to present-day observed thickness and flow field (Pattyn, 2017). The model is forced by present-day SMB and temperature (van Wessem et al., 2014), based on the output of the regional atmospheric climate model RACMO2 for the period 1979-2011. The PICO model (Reese et al., 2018) was employed to calculate sub-shelf melt rates, based on present-day observed ocean temperature and salinity (Schmidtko et al., 2014) on which the initMIP forcings for the different basins are added. The model is run on a regular grid of $16 \mathrm{~km}$ with time steps of 0.05 year.

\section{B16 VUB_AISMPALEO}

The Antarctic ice sheet model from the Vrije Universiteit Brussel is derived from the coarse-resolution version used mainly in simulations of the glacial cycles (Huybrechts, 1990, 2002). It considers thermomechanically coupled flow in both the ice sheet and the ice shelf, using the shallow ice approximation-shallow ice shelf approximation coupled across a transition zone one grid cell wide. Basal sliding is calculated using a Weertman relation inversely proportional to the height above buoyancy wherever the ice is at the pressure melting point. The horizontal resolution is $20 \mathrm{~km}$, and there are 31 layers in the vertical. The model is initialized with a freely evolving geometry until a steady state is reached. The precipitation pattern is based on the Giovinetto and Zwally (2000) compilation used in Huybrechts et al. (2000), updated with accumulation rates obtained from shallow ice cores during the EPICA pre-site surveys (Huybrechts et al., 2007). Surface melting is calculated over the entire model domain with the PDD scheme, including meltwater retention by refreezing and capillary forces in the snowpack (Janssens and Huybrechts, 2000). The subshelf basal melt rate is parameterized as a function of local mid-depth $(485-700 \mathrm{~m})$ ocean-water temperature above the freezing point (Beckmann and Goosse, 2003). A distinction is made between protected ice shelves (Ross and FilchnerRonne) with a low melt factor and all other ice shelves with a higher melt factor. Ocean temperatures are derived from the LOVECLIM climate model (Goelzer et al., 2016), and parameters are chosen to reproduce observed average melt rates (Depoorter et al., 2013). Heat conduction is calculated in a slab of bedrock $4 \mathrm{~km}$ thick underneath the ice sheet. Isostatic compensation is based on an elastic lithosphere floating on a viscous asthenosphere (ELRA model) but is not allowed 
to evolve further in line with the initMIP-Antarctica experiments. 
Appendix C: Modeled initial conditions

Table C1. Simulated Antarctic initial ice-covered extent, ice shelf extent, ice mass, ice mass above floatation, total SMB, and total basal melt.

\begin{tabular}{|c|c|c|c|c|c|c|}
\hline Model name & $\begin{array}{l}\text { Ice extent } \\
\left(10^{6} \mathrm{~km}^{2}\right)\end{array}$ & $\begin{array}{l}\text { Ice shelf extent } \\
\qquad\left(10^{6} \mathrm{~km}^{2}\right)\end{array}$ & $\begin{array}{l}\text { Ice mass } \\
\left(10^{7} \mathrm{Gt}\right)\end{array}$ & $\begin{array}{r}\text { Ice mass above } \\
\text { floatation }\left(10^{7} \mathrm{Gt}\right)\end{array}$ & $\begin{array}{r}\text { Surface mass } \\
\text { balance }(\mathrm{Gt})\end{array}$ & $\begin{array}{r}\text { Basal melt } \\
(\mathrm{Gt})\end{array}$ \\
\hline ARC_PISM1 & 13.696 & 1.2348 & 2.5289 & 2.4656 & 2686 & 0 \\
\hline ARC_PISM2 & 13.696 & 1.2348 & 2.5289 & 2.4656 & 2686 & 0 \\
\hline ARC_PISM3 & 13.579 & 1.1466 & 2.3302 & 2.2785 & 2493 & 50 \\
\hline ARC_PISM4 & 13.579 & 1.1463 & 2.3302 & 2.2785 & 2493 & 49 \\
\hline AWI_PISM1Eq & 14.112 & 1.3885 & 2.4482 & 2.0979 & 2672 & 1233 \\
\hline AWI_PISM1Pal & 14.669 & 1.4364 & 2.5602 & 2.1544 & 3061 & 1581 \\
\hline CPOM_BISICLES_A & 13.654 & 1.5338 & 2.4118 & 2.0734 & 2144 & 2141 \\
\hline CPOM_BISICLES_B & 13.654 & 1.5338 & 2.4118 & 2.0734 & 2144 & 2141 \\
\hline DMI_PISM0 & 14.270 & 2.0408 & 2.1068 & 1.7873 & 3427 & 152 \\
\hline DMI_PISM1 & 14.270 & 2.0411 & 2.1068 & 1.7873 & 3427 & 451 \\
\hline DOE_MALI & 13.595 & 1.4623 & 2.3794 & 2.0467 & 2415 & 562 \\
\hline IGE_ELMER & 13.590 & 1.3456 & 2.3885 & 2.0523 & 2515 & 784 \\
\hline ILTS_SICOPOLIS1 & 13.609 & 1.1942 & 2.4050 & 2.0781 & 2020 & 456 \\
\hline ILTS_SICOPOLIS2 & 13.591 & 1.2643 & 2.4092 & 2.0854 & 2015 & 508 \\
\hline IMAU_IMAUICE32 & 14.174 & 1.2318 & 2.3535 & 2.0573 & 2706 & 0 \\
\hline JPL1_ISSM & 13.905 & 1.4522 & 2.4382 & 2.1074 & 2337 & 986 \\
\hline LSCE_GRISLI & 13.956 & 1.1991 & 2.4504 & 2.1081 & 2602 & 1565 \\
\hline NCAR_CISM & 13.500 & 1.1850 & 2.3640 & 2.0422 & 2469 & 1125 \\
\hline PIK_PISM3PAL & 14.556 & 1.2273 & 2.3574 & 2.0069 & 3191 & 583 \\
\hline PIK_PISM4EQUI & 14.230 & 0.9168 & 2.3993 & 2.0466 & 2795 & 304 \\
\hline PSU_EQNOMEC & 15.043 & 2.2700 & 2.4962 & 1.8772 & 2639 & 1278 \\
\hline PSU_GLNOMEC & 15.003 & 2.5063 & 2.4970 & 1.8888 & 2679 & 1417 \\
\hline UCIJPL_ISSM & 13.784 & 1.3217 & 2.4289 & 2.1142 & 2519 & 683 \\
\hline ULB_FETISH1 & 13.889 & 1.6328 & 2.3972 & 2.0612 & 2660 & 2468 \\
\hline VUB_AISMPALEO & 14.241 & 1.2167 & 2.5007 & 2.1603 & 2435 & 278 \\
\hline
\end{tabular}


Appendix D: Modeled sea level contribution for all experiments

Table D1. Antarctic contribution to sea level ( $\mathrm{mm}$ sea level equivalent, positive for sea level increase) at the end of the 100-year simulation for the three experiments and all submissions.

\begin{tabular}{lrrr}
\hline Model name & $\mathrm{ctrl}$ & $\mathrm{asmb}$ & $\mathrm{abmb}$ \\
\hline ARC_PISM1 & -112.9 & -287.1 & 66.5 \\
ARC_PISM2 & -115.0 & -300.6 & 154.7 \\
ARC_PISM3 & -5.5 & -151.3 & 88.6 \\
ARC_PISM4 & -2.4 & -154.9 & 215.4 \\
AWI_PISM1Eq & -22.1 & -172.3 & 22.7 \\
AWI_PISM1Pal & -48.4 & -213.0 & -4.5 \\
CPOM_BISICLES_A & 26.9 & -110.4 & 105.3 \\
CPOM_BISICLES_B & 83.3 & -54.3 & 169.1 \\
DMI_PISM0 & 0.8 & -140.1 & 94.4 \\
DMI_PISM1 & -4.1 & -140.0 & 108.8 \\
DOE_MALI & 167.3 & -26.6 & 249.9 \\
IGE_ELMER & -11.5 & -255.6 & -98.3 \\
ILTS_SICOPOLIS1 & -107.5 & -251.8 & -84.9 \\
ILTS_SICOPOLIS2 & -115.3 & -262.7 & -80.0 \\
IMAU_IMAUICE32 & 0.1 & -146.7 & 108.9 \\
JPL1_ISSM & -80.7 & -236.8 & 7.4 \\
LSCE_GRISLI & -167.6 & -324.6 & -149.6 \\
NCAR_CISM & 4.1 & -137.4 & 39.3 \\
PIK_PISM3PAL & -12.2 & -167.8 & 365.7 \\
PIK_PISM4EQUI & -19.8 & -181.4 & 407.0 \\
PSU_EQNOMEC & 12.7 & -112.0 & 47.5 \\
PSU_GLNOMEC & 16.2 & -108.9 & 50.7 \\
UCIJPL_ISSM & -243.6 & -400.0 & -178.5 \\
ULB_FETISH1 & -47.4 & -209.7 & -22.0 \\
VUB_AISMPALEO & -9.4 & -169.5 & 79.7 \\
\hline
\end{tabular}


Competing interests. The authors declare that they have no conflict of interest.

Special issue statement. This article is part of the special issue "The Ice Sheet Model Intercomparison Project for CMIP6 (ISMIP6)". It is not associated with a conference.

Acknowledgements. We acknowledge the Climate and Cryosphere (CliC) project and the World Climate Research Programme (WCRP) for their guidance, support, and sponsorship. We thank the CMIP6 panel members for their continuous leadership of the CMIP6 effort and the Working Group on Coupled Modeling (WGCM) Infrastructure Panel (WIP) for overseeing the CMIP6 and ISMIP6 infrastructure and data request. Research was carried out at the Jet Propulsion Laboratory, California Institute of Technology, under a contract with the National Aeronautics and Space Administration (80NM0018D0004). Hélène Seroussi, Nicole-Jeanne Schlegel, Eric Larour, Sophie Nowicki, and Erika Simon are supported by grants from the NASA Cryospheric Science, Sea Level Change Team, and Modeling Analysis and Prediction Program. Material is based upon work supported by the National Center for Atmospheric Research, which is a major facility sponsored by the National Science Foundation under Cooperative Agreement no. 1852977. Computing and data storage resources for CISM simulations, including the Cheyenne supercomputer (https://doi.org/10.5065/D6RX99HX), were provided by the Computational and Information Systems Laboratory (CISL) at NCAR. Ralf Greve was supported by the Japan Society for the Promotion of Science (JSPS) KAKENHI grant numbers JP16H02224, JP17H06104, and JP17H06323. Christian Rodehacke (DMI) has received funding from the European Research Council under the European Community's Seventh Framework Programme (FP7) for research, and Theme 6 Environment as part of the NACLIM (North Atlantic Climate) project (grant agreement 308299), as well as the Nordic Centers of Excellence eSTICC (eScience Tool for Investigating Climate Change at High Northern Latitudes) funded by Nordforsk (grant 57001). Support for Matthew J. Hoffman, Stephen F. Price, and Tong Zhang was provided through the Scientific Discovery through Advanced Computing (SciDAC) program funded by the US Department of Energy Office of Science, Biological and Environmental Research and Advanced Scientific Computing Research programs. This research used resources of the National Energy Research Scientific Computing Center, a DOE Office of Science User Facility supported by the Office of Science of the US Department of Energy under contract no. DEAC02-05CH11231. The Ministry of Education, Culture and Science (OCW), in the Netherlands, provided financial support for this study via the program of the Netherlands Earth System Science Centre (NESSC). The work of Thomas Kleiner and Angelika Humbert has been conducted in the framework of the PalMod project (FKZ: 01LP1511B), supported by the German Federal Ministry of Education and Research (BMBF) as Research for Sustainability initiative (FONA). Aurélien Quiquet acknowledges funding from the European Research Council grant ACCLIMATE no. 339108. Fabien Gillet-Chaulet and Julien Brondex (IGE) have received funding from the French National Research Agency (ANR) under the TROIS-AS project (ANR-15-CE01-0005-01). IGE-ELMER simu- lations were performed using HPC resources from GENCI-CINES (grant 2017-016066) and using the Froggy platform of the CIMENT infrastructure, which is supported by the Rhone-Alpes region (grant CPER07_13 CIRA), the OSUG@2020 laBex (reference ANR10 LABX56), and the Equip@Meso project (reference ANR-10-EQPX-29-01). Torsten Albrecht was supported by the Deutsche Forschungsgemeinschaft (DFG) in the framework of the priority program "Antarctic Research with comparative investigations in Arctic ice areas" by grant LE1448/6-1 and LE1448/7-1. Matthias Mengel was supported by the DFG in the same framework by grant WI 4556/4-1. Development of PISM is supported by NASA grant NNX17AG65G and NSF grants PLR-1603799 and PLR-1644277. The authors gratefully acknowledge the European Regional Development Fund (ERDF), the German Federal Ministry of Education and Research, and the Land Brandenburg for supporting this project by providing resources on the high-performance computer system at the Potsdam Institute for Climate Impact Research. Computer resources for this project have also been provided by the Gauss Centre for Supercomputing/Leibniz Supercomputing Centre under Project-ID pr94ga. Mathieu Morlighem was supported by a grant from the National Science Foundation, Office of Polar Programs (OPP; grant no. 1443229). Sainan Sun was supported by the FRS-FNRS MEDRISM project and the BELSPO MIMO project (Stereo III). Philippe Huybrechts and Jonas Van Breedam acknowledge support from the iceMOD project funded by the Research Foundation - Flanders (FWO-Vlaanderen). Daniel Lowry acknowledges support from the Antarctica New Zealand Doctoral Scholarship program and the New Zealand Ministry of Business, Innovation and Employment (grant 15-VUW-131).

Review statement. This paper was edited by Kenichi Matsuoka and reviewed by Jesse Johnson and one anonymous referee.

\section{References}

Agosta, C., Amory, C., Kittel, C., Orsi, A., Favier, V., Gallée, H., van den Broeke, M. R., Lenaerts, J. T. M., van Wessem, J. M., van de Berg, W. J., and Fettweis, X.: Estimation of the Antarctic surface mass balance using the regional climate model MAR (19792015) and identification of dominant processes, The Cryosphere, 13, 281-296, https://doi.org/10.5194/tc-13-281-2019, 2019.

Arthern, R. and Williams, C.: The sensitivity of West Antarctica to the submarine melting feedback, Geophys. Res. Lett., 44, 23522359, https://doi.org/10.1002/2017GL072514, 2017.

Arthern, R. J., Winebrenner, D., and Vaughan, D.: Antarctic snow accumulation mapped using polarization of $4.3-\mathrm{cm}$ wavelength microwave emission, J. Geophys. Res., 111, D06107, https://doi.org/10.1029/2004JD005667, 2006.

Arthern, R. J., Hindmarsh, R. C. A., and Williams, C. R.: Flow speed within the Antarctic ice sheet and its controls inferred from satellite observations, J. Geophys. Res., 120, 1171-1188, https://doi.org/10.1002/2014JF003239, 2015.

Asay-Davis, X. S., Jourdain, N. C., and Nakayama, Y.: Developments in Simulating and Parameterizing Interactions between the Southern Ocean and the Antarctic Ice Sheet, Current Climate Change Reports manuscript, 3, 316-329, https://doi.org/10.1007/s40641-017-0071-0, 2017. 
Aschwanden, A., Bueler, E., Khroulev, C., and Blatter, H.: An enthalpy formulation for glaciers and ice sheets, J. Glaciol., 58, 441-457, https://doi.org/10.3189/2012JoG11J088, 2012.

Aschwanden, A., Aðalgeirsdóttir, G., and Khroulev, C.: Hindcasting to measure ice sheet model sensitivity to initial states, The Cryosphere, 7, 1083-1093, https://doi.org/10.5194/tc-7-10832013, 2013.

Banwell, A. F., MacAyeal, D. R., and Sergienko, O. V.: Breakup of the Larsen B Ice Shelf triggered by chain reaction drainage of supraglacial lakes, Geophys. Res. Lett., 40, 5872-5876, https://doi.org/10.1002/2013GL057694, 2013.

Bassis, J. N. and Ma, Y.: Evolution of basal crevasses links ice shelf stability to ocean forcing, Earth Planet. Sc. Lett., 409, 203-211, https://doi.org/10.1016/j.epsl.2014.11.003, 2015.

Beckmann, A. and Goosse, H.: A parameterization of ice shelfocean interaction for climate models, Ocean Model., 5, 157-170, 2003.

Bernales, J., Rogozhina, I., Greve, R., and Thomas, M.: Comparison of hybrid schemes for the combination of shallow approximations in numerical simulations of the Antarctic Ice Sheet, The Cryosphere, 11, 247-265, https://doi.org/10.5194/tc11-247-2017, 2017.

Berrisford, P., Dee, D., Fielding, K., Fuentes, M., Kallberg, P., Kobayashi, S., and Uppala, S.: The ERAInterim Archive Version 2.0, Tech. Rep., Reading, UK, ECMWF, available at: https://www.ecmwf.int/en/elibrary/ 8174-era-interim-archive-version-20 (last access: 8 May 2019), 2011.

Bindschadler, R., Nowicki, S., Abe-Ouchi, A., Aschwanden, A., Choi, H., Fastook, J., Granzow, G., Greve, R., Gutowski, G., Herzfeld, U., Jackson, C., Johnson, J., Khroulev, C., Levermann, A., Lipscomb, W., Martin, M., Morlighem, M., Parizek, B., Pollard, D., Price, S., Ren, D., Saito, F., Sato, T., Seddik, H., Seroussi, H., Takahashi, K., Walker, R., and Wang, W.: Ice-Sheet Model Sensitivities to Environmental Forcing and Their Use in Projecting Future Sea-Level (The SeaRISE Project), J. Glaciol., 59, 195-224, https://doi.org/10.3189/2013JoG12J125, 2013.

Blatter, H.: Velocity And Stress-Fields In Grounded Glaciers: A Simple Algorithm For Including Deviatoric Stress Gradients, J. Glaciol., 41, 333-344, 1995.

Bueler, E. and Brown, J.: Shallow shelf approximation as a "sliding law" in a thermomechanically coupled ice sheet model, J. Geophys. Res., 114, 1-21, https://doi.org/10.1029/2008JF001179, 2009.

Bueler, E. and van Pelt, W.: Mass-conserving subglacial hydrology in the Parallel Ice Sheet Model version 0.6, Geosci. Model Dev., 8, 1613-1635, https://doi.org/10.5194/gmd-8-1613-2015, 2015.

Bueler, E., Brown, J., and Lingle, C.: Exact solutions to the thermomechanically coupled shallow-ice approximation: effective tools for verification, J. Glaciol., 53, 499-516, 2007.

Christie, F. D. W., Bingham, R. G., Gourmelen, N., Tett, S. F. B., and Muto, A.: Four-decade record of pervasive grounding line retreat along the Bellingshausen margin of West Antarctica, Geophys. Res. Lett., 43, 5741-5749, https://doi.org/10.1002/2016GL068972, 2016.

Christie, F. D. W., Bingham, R. G., Gourmelen, N., Steig, E. J., Bisset, R. R., Pritchard, H. D., Snow, K., and Tett, S. F. B.: Glacier change along West Antarctica's Marie Byrd Land Sector and links to inter-decadal atmosphere-ocean variability, The
Cryosphere, 12, 2461-2479, https://doi.org/10.5194/tc-12-24612018, 2018.

Church, J., Clark, P., Cazenave, A., Gregory, J., Jevrejeva, S., Levermann, A., Merrifield, M., Milne, G., Nerem, R., Nunn, P., Payne, A., Pfeffer, W., Stammer, D., and Unnikrishnan, A.: Climate Change 2013: The Physical Science Basis Change, book section 13, Cambridge University Press, Cambridge, United Kingdom and New York, NY, USA, 1137-1216, https://doi.org/10.1017/CBO9781107415324.026, 2013.

Comiso, J.: Variability and trends in Antarctic surface temperatures from in situ and satellite infrared measurements, J. Clim., 13, 1674-1696, 2000.

Cornford, S., Martin, D., Graves, D., Ranken, D. F., Le Brocq, A. M., Gladstone, R., Payne, A., Ng, E., and Lipscomb, W.: Adaptive mesh, finite volume modeling of marine ice sheets, J. Comput. Phys., 232, 529-549, https://doi.org/10.1016/j.jcp.2012.08.037, 2013.

Cornford, S. L., Martin, D. F., Payne, A. J., Ng, E. G., Le Brocq, A. M., Gladstone, R. M., Edwards, T. L., Shannon, S. R., Agosta, C., van den Broeke, M. R., Hellmer, H. H., Krinner, G., Ligtenberg, S. R. M., Timmermann, R., and Vaughan, D. G.: Centuryscale simulations of the response of the West Antarctic Ice Sheet to a warming climate, The Cryosphere, 9, 1579-1600, https://doi.org/10.5194/tc-9-1579-2015, 2015.

Cornford, S. L., Martin, D. F., Lee, V., Payne, A. J., and Ng, E.: Adaptive mesh refinement versus subgrid friction interpolation in simulations of Antarctic ice dynamics, Ann. Glaciol., 73, 1-9, https://doi.org/10.1017/aog.2016.13, 2016.

De Angelis, H. and Skvarca, P.: Glacier surge after ice shelf collapse, Science, 299, 1560-1562, https://doi.org/10.1126/science.1077987, 2003.

de Boer, B., Stocchi, P., and van de Wal, R. S. W.: A fully coupled 3D ice-sheet-sea-level model, algorithm and applications, Geosci. Model Dev., 7, 2141-2156, https://doi.org/10.5194/gmd-7-21412014, 2014.

DeConto, R. and Pollard, D.: Contribution of Antarctica to past and future sea-level rise, Nature, 531, 591-597, https://doi.org/10.1038/nature17145, 2016.

Dee, D. P., Uppala, S. M., Simmons, A. J., Berrisford, P., Poli, P., Kobayashi, S., and Vitart, F.: The ERA-Interim reanalysis: configuration and performance of the data assimilation system, Q. J. Roy. Meteor. Soc., 137, 553-597, https://doi.org/10.1002/qj.828, 2011.

Depoorter, M. A., Bamber, J. L., Griggs, J. A., Lenaerts, J. T. M., Ligtenberg, S. R. M., van den Broeke, M. R., and Moholdt, G.: Calving fluxes and basal melt rates of Antarctic ice shelves, Nature, 502, 89-92, https://doi.org/10.1038/nature12567, 2013.

Doake, C. S. M. and Vaughan, D. G.: Rapid disintegration of the Wordie Ice Shelf in response to atmospheric warming, Nature, 350, 328-330, 1991.

Donat-Magnin, M., Jourdain, N. C., Spence, P., Le Sommer, J., Gallee, H., and Durand, G.: Ice-Shelf Melt Response to Changing Winds and Glacier Dynamics in the Amundsen Sea Sector, Antarctica, J. Geophys. Res., 122, 10206-10224, https://doi.org/10.1002/2017JC013059, 2017.

Favier, L., Durand, G., Cornford, S. L., Gudmundsson, G. H., Gagliardini, O., Gillet-Chaulet, F., Zwinger, T., Payne, A. J., and Le Brocq, A.: Retreat of Pine Island Glacier controlled 
by marine ice-sheet instability, Nat. Clim. Change, 4, 117-121, https://doi.org/10.1038/NCLIMATE2094, 2014.

Feldmann, J., Albrecht, T., Khroulev, C., F., P., and Levermann, A.: Resolution-dependent performance of grounding line motion in a shallow model compared with a full-Stokes model according to the MISMIP3d intercomparison, J. Glaciol., 60, 353-359, https://doi.org/10.3189/2014JoG13J093, 2014.

Fortuin, J. P. F. and Oerlemans, J.: Parameterization of the annual surface temperature and mass balance of Antarctica, Ann. Glaciol., 14, 78-84, 1990.

Fretwell, P., Pritchard, H. D., Vaughan, D. G., Bamber, J. L., Barrand, N. E., Bell, R., Bianchi, C., Bingham, R. G., Blankenship, D. D., Casassa, G., Catania, G., Callens, D., Conway, H., Cook, A. J., Corr, H. F. J., Damaske, D., Damm, V., Ferraccioli, F., Forsberg, R., Fujita, S., Gim, Y., Gogineni, P., Griggs, J. A., Hindmarsh, R. C. A., Holmlund, P., Holt, J. W., Jacobel, R. W., Jenkins, A., Jokat, W., Jordan, T., King, E. C., Kohler, J., Krabill, W., Riger-Kusk, M., Langley, K. A., Leitchenkov, G., Leuschen, C., Luyendyk, B. P., Matsuoka, K., Mouginot, J., Nitsche, F. O., Nogi, Y., Nost, O. A., Popov, S. V., Rignot, E., Rippin, D. M., Rivera, A., Roberts, J., Ross, N., Siegert, M. J., Smith, A. M., Steinhage, D., Studinger, M., Sun, B., Tinto, B. K., Welch, B. C., Wilson, D., Young, D. A., Xiangbin, C., and Zirizzotti, A.: Bedmap2: improved ice bed, surface and thickness datasets for Antarctica, The Cryosphere, 7, 375-393, https://doi.org/10.5194/tc-7-375-2013, 2013.

Fürst, J., Durand, G., Gillet-Chaulet, F., Merino, N., Tavard, L., Mouginot, J., Gourmelen, N., and Gagliardini, O.: Assimilation of Antarctic velocity observations provides evidence for uncharted pinning points, The Cryosphere, 9, 1427-1443, https://doi.org/10.5194/tc-9-1427-2015, 2015.

Fürst, J., Durand, G., Gillet-Chaulet, F., Tavard, T., Rankl, M., Braun, M., and Gagliardini, O.: The safety band of Antarctic ice shelves, Nat. Clim. Change, 6, 479-482, https://doi.org/10.1038/NCLIMATE2912, 2016.

Gillet-Chaulet, F., Gagliardini, O., Seddik, H., Nodet, M., Durand, G., Ritz, C., Zwinger, T., Greve, R., and Vaughan, D.: Greenland Ice Sheet contribution to sea-level rise from a newgeneration ice-sheet model, The Cryosphere, 6, 1561-1576, https://doi.org/10.5194/tc-6-1561-2012, 2012.

Giovinetto, M. B. and Zwally, H. J.: Spatial distribution of net surface accumulation on the Antarctic ice sheet, Ann. Glaciol., 31, $171-178,2000$

Gladstone, R. M., Payne, A. J., and Cornford, S. L.: Parameterising the grounding line in flow-line ice sheet models, The Cryosphere, 4, 605-619, https://doi.org/10.5194/tc-4-605-2010, 2010.

Goelzer, H., Huybrechts, P., Loutre, M.-F., and Fichefet, T.: Last Interglacial climate and sea-level evolution from a coupled ice sheet-climate model, Clim. Past, 12, 2195-2213, https://doi.org/10.5194/cp-12-2195-2016, 2016.

Goelzer, H., Nowicki, S., Edwards, T., Beckley, M., Abe-Ouchi, A., Aschwanden, A., Calov, R., Gagliardini, O., Gillet-Chaulet, F., Golledge, N. R., Gregory, J., Greve, R., Humbert, A., Huybrechts, P., Kennedy, J. H., Larour, E., Lipscomb, W. H., Leclec'h, S., Lee, V., Morlighem, M., Pattyn, F., Payne, A. J., Rodehacke, C., Ruckamp, M., Saito, F., Schlegel, N., Seroussi, H., Shepherd, A., Sun, S., van de Wal, R., and Ziemen, F. A.: Design and results of the ice sheet model initialisation experiments initMIP-Greenland: an ISMIP6 intercomparison, The
Cryosphere, 12, 1433-1460, https://doi.org/10.5194/tc-12-14332018, 2018.

Goldberg, D. N.: A variationally derived, depth-integrated approximation to a higher-order glaciological flow model, J. Glaciol., 57, 157-170, https://doi.org/10.3189/002214311795306763, 2011.

Goldberg, D. N., Heimbach, P., Joughin, I., and Smith, B.: Committed retreat of Smith, Pope, and Kohler Glaciers over the next 30 years inferred by transient model calibration, The Cryosphere, 9 , 2429-2446, https://doi.org/10.5194/tc-9-2429-2015, 2015.

Golledge, N. R., Kowalewski, D. E., Naish, T. R., Levy, R. H., Fogwill, C. J., and Gasson, E. G. W.: The multi-millennial Antarctic commitment to future sea-level rise, Nature, 526, 421-425, https://doi.org/10.1038/nature15706, 2015.

Greenbaum, J. S., Blankenship, D. D., Young, D. A., Richter, T. G., Roberts, J. L., Aitken, A. R. A., Legresy, B., Schroeder, D. M., Warner, R. C., van Ommen, T. D., and Siegert, M. J.: Ocean access to a cavity beneath Totten Glacier in East Antarctica, Nat. Geosci., 8, 294-298, https://doi.org/10.1038/NGEO2388, 2015.

Greve, R. and Blatter, H.: Comparison of thermodynamics solvers in the polythermal ice sheet model SICOPOLIS, Polar Sci., 10, 11-23, https://doi.org/10.1016/j.polar.2015.12.004, 2016.

Greve, R. and Galton-Fenzi, B.: InitMIP-Antarctica experiments with the ice sheet model SICOPOLIS, Abstract No. MIS10-01, JpGU-AGU Joint Meeting, Makuhari, Chiba, Japan, May 2017, 2017.

Greve, R. and Herzfeld, U. C.: Resolution of ice streams and outlet glaciers in large-scale simulations of the Greenland ice sheet, Ann. Glaciol., 54, 209-220, https://doi.org/10.3189/2013AoG63A085, 2013.

Hellmer, H. and Olber, D.: A two-dimensional model of the thermohaline circulation under an ice shelf, Antarct. Sci., 1, 325-336, 1989.

Hindmarsh, R.: A numerical comparison of approximations to the Stokes equations used in ice sheet and glacier modeling, J. Geophys. Res., 109, 1-15, https://doi.org/10.1029/2003JF000065, 2004.

Hoffman, M. J., Perego, M., Price, S. F., Lipscomb, W. H., Zhang, T., Jacobsen, D., Tezaur, I., Salinger, A. G., Tuminaro, R., and Bertagna, L.: MPAS-Albany Land Ice (MALI): a variable-resolution ice sheet model for Earth system modeling using Voronoi grids, Geosci. Model Dev., 11, 3747-3780, https://doi.org/10.5194/gmd-11-3747-2018, 2018.

Hutter, K.: Theoretical glaciology: material science of ice and the mechanics of glaciers and ice sheets, D. Reidel Publishing Co, Dordrecht, the Netherlands, 1983.

Huybrechts, P.: A 3-D model for the Antarctic ice sheet: a sensitivity study on the glacial-interglacial contrast, Clim. Dynam., 5, 7992, 1990.

Huybrechts, P., Steinhage, D., Wilhelms, F., and Bamber, J.: Balance velocities and measured properties of the Antarctic ice sheet from a new compilation of gridded data for modelling, Ann. Glaciol., 30, 52-60, 2000.

Huybrechts, P.: Sea-level changes at the LGM from ice-dynamic reconstructions of the Greenland and Antarctic ice sheets during the glacial cycles, Quaternary Sci. Rev., 21, 203-231, 2002.

Huybrechts, P., Rybak, O., Pattyn, F., Ruth, U., and Steinhage, D.: Ice thinning, upstream advection, and non-climatic biases for the upper $89 \%$ of the EDML ice core from a nested 
model of the Antarctic ice sheet, Clim. Past, 3, 577-589, https://doi.org/10.5194/cp-3-577-2007, 2007.

Jacobs, S., Jenkins, A., Hellmer, H., Giulivi, C., Nitsche, F., Huber, B., and Guerrero, R.: The Amundsen Sea and the Antarctic Ice Sheet, Oceanography, 25, 154-163, https://doi.org/10.5670/oceanog.2012.90, 2012.

Jacobs, S. S., Jenkins, A., Giulivi, C. F., and Dutrieux, P.: Stronger ocean circulation and increased melting under Pine Island Glacier ice shelf, Nat. Geosci., 4, 519-523, https://doi.org/10.1038/NGEO1188, 2011.

Janssens, I. and Huybrechts, P.: The treatment of meltwater retention in mass-balance parameterizations of the Greenland ice sheet, Ann. Glaciol., 31, 133-140, 2000.

Jenkins, A., Dutrieux, P., Jacobs, S., McPhail, S., Perrett, J., Webb, A., and White, D.: Observations beneath Pine Island Glacier in West Antarctica and implications for its retreat, Nat. Geosci., 3, 468-472, 2010.

Jenkins, A., Shoosmith, D., Dutrieux, P., Jacobs, S., Kim, T. W., Lee, S. H., Ha, H. K., and Stammerjohn, S.: West Antarctic Ice Sheet retreat in the Amundsen Sea driven by decadal oceanic variability, Nat. Geosci., 11, 733-738, https://doi.org/10.1038/s41561-018-0207-4, 2018.

Jones, P. W.: First- and Second-Order Conservative Remapping Schemes for Grids in Spherical Coordinates, Mon. Weather Rev., 127, 2204, https://doi.org/10.1175/15200493(1999)127<2204:FASOCR>2.0.CO;2, 1999.

Joughin, I., Smith, B., and Medley, B.: Marine Ice Sheet Collapse Potentially Underway for the Thwaites Glacier Basin, West Antarctica, Science, 344, 735-738, https://doi.org/10.1126/science.1249055, 2014.

Jouzel, J., Masson-Delmotte, V., Cattani, O., Dreyfus, G., Falourd, S., Hoffmann, G., Minster, B., Nouet, J., Barnola, J. M., Chappellaz, J., Fischer, H., Gallet, J. C., Johnsen, S., Leuenberger, M., Loulergue, L., Luethi, D., Oerter, H., Parrenin, F., Raisbeck, G., Raynaud, D., Schilt, A., Schwander, J., Selmo, E., Souchez, R., Spahni, R., Stauffer, B., Steffensen, J. P., Stenni, B., Stocker, T. F., Tison, J. L., Werner, M., and Wolff, E. W.: Orbital and Millennial Antarctic Climate Variability over the Past 800,000 Years, Science, 317, 793-796, https://doi.org/10.1126/science.1141038, 2007.

Khazendar, A., Schodlok, M., Fenty, I., Ligtenberg, S., Rignot, E., and van den Broeke, M.: Observed thinning of Totten Glacier is linked to coastal polynya variability, Nat. Commun., 4, 2857, https://doi.org/10.1038/ncomms3857, 2013.

Larour, E., Utke, J., Csatho, B., Schenk, A., Seroussi, H., Morlighem, M., Rignot, E., Schlegel, N., and Khazendar, A.: Inferred basal friction and surface mass balance of the Northeast Greenland Ice Stream using data assimilation of ICESat (Ice Cloud and land Elevation Satellite) surface altimetry and ISSM (Ice Sheet System Model), The Cryosphere, 8, 2335-2351, https://doi.org/10.5194/tc-8-2335-2014, 2014.

Le Brocq, A. M., Payne, A. J., and Vieli, A.: An improved Antarctic dataset for high resolution numerical ice sheet models (ALBMAP v1), Earth Syst. Sci. Data, 2, 247-260, https://doi.org/10.5194/essd-2-247-2010, 2010.

Le clec'h, S., Quiquet, A., Charbit, S., Dumas, C., Kageyama, M., and Ritz, C.: A rapidly converging spin-up method for the present-day Greenland ice sheet using the
GRISLI ice-sheet model, Geosci. Model Dev. Discuss., https://doi.org/10.5194/gmd-2017-322, in review, 2018.

Leguy, G., Asay-Davis, X., and Lipscomb, W.: Parameterization of basal friction near grounding lines in a onedimensional ice sheet model, The Cryosphere, 8, 1239-1259, https://doi.org/10.5194/tc-8-1239-2014, 2014.

Lenaerts, J. T. M., van den Broeke, M. R., van de Berg, W. J., van Meijgaard, E., and Munneke, P. K.: A new, high-resolution surface mass balance map of Antarctica (1979-2010) based on regional atmospheric climate modeling, Geophys. Res. Lett., 39, 1-5, https://doi.org/10.1029/2011GL050713, 2012.

Levermann, A., Albrecht, T., Winkelmann, R., Martin, M. A., Haseloff, M., and Joughin, I.: Kinematic first-order calving law implies potential for abrupt ice-shelf retreat, The Cryosphere, 6, 273-286, https://doi.org/10.5194/tc-6-273-2012, 2012.

Levitus, S., Antonov, J. I., Boyer, T. P., Baranova, O. K., Garcia, H. E., Locarnini, R. A., Mishonov, A. V., Reagan, J. R., Seidov, D., Yarosh, E. S., and Zweng, M. M.: World ocean heat content and thermosteric sea level change (0-2000 m), 1955-2010, Geophys. Res. Lett., 39, L10603, https://doi.org/10.1029/2012GL051106, 2012.

Ligtenberg, S. R. M., van de Berg, W. J., van den Broeke, M. R., Rae, J. G. L., and van Meijgaard, E.: Future surface mass balance of the Antarctic ice sheet and its influence on sea level change, simulated by a regional atmospheric climate model, Clim. Dynam., 41, 867-884, https://doi.org/10.1007/s00382-013-1749-1, 2013.

Lipscomb, W. H., Price, S. F., Hoffman, M. J., Leguy, G. R., Bennett, A. R., Bradley, S. L., Evans, K. J., Fyke, J. G., Kennedy, J. H., Perego, M., Ranken, D. M., Sacks, W. J., Salinger, A. G., Vargo, L. J., and Worley, P. H.: Description and evaluation of the Community Ice Sheet Model (CISM) v2.1, Geosci. Model Dev., 12, 387-424, https://doi.org/10.5194/gmd-12-387-2019, 2019.

Locarnini, R. A., Mishonov, A. V., Antonov, J. I., Boyer, T. P., Garcia, H. E., Baranova, O. K., Zweng, M. M., and Johnson, D. R. World Ocean Atlas 2009, Volume 1: Temperature, US Government Printing Office, Washington, DC, https://www.nodc.noaa. gov/OC5/WOA09/pubwoa09.html (last access: 9 May 2019), 2010.

MacAyeal, D.: Binge/Purge oscillations of the Laurentide ice-sheet as a cause of the North-Atlantic's Heinrich events, Paleoceanography, 8, 775-784, 1993.

MacAyeal, D. R.: Large-scale ice flow over a viscous basal sediment: Theory and application to Ice Stream B, Antarctica, J. Geophys. Res., 94, 4071-4087, 1989.

Martin, M. A., Winkelmann, R., Haseloff, M., Albrecht, T., Bueler, E., Khroulev, C., and Levermann, A.: The Potsdam Parallel Ice Sheet Model (PISM-PIK) - Part 2: Dynamic equilibrium simulation of the Antarctic ice sheet, The Cryosphere, 5, 727-740, https://doi.org/10.5194/tc-5-727-2011, 2011.

Maule, C. F., Purucker, M. E., Olsen, N., and Mosegaard, K.: Heat Flux Anomalies in Antarctica Revealed by Satellite Magnetic Data, Science, 309, 464-467, https://doi.org/10.1126/science.1106888, 2005.

Millan, R., Rignot, E., Bernier, V., Morlighem, M., and Dutrieux, P.: Bathymetry of the Amundsen Sea Embayment sector of West Antarctica from Operation IceBridge gravity and other data, Geophys. Res. Lett., 44, 1360-1368, https://doi.org/10.1002/2016GL072071, 2017. 
Miller, K. G., Wright, J. D., Browning, J. V., Kulpecz, A., Kominz, M., Naish, T. R., Cramer, B. S., Rosenthal, Y., Peltier, W. R., and Sosdian, S.: High tide of the warm Pliocene: Implications of global sea level for Antarctic deglaciation, Geology, 40, 407410, https://doi.org/10.1130/G32869.1, 2012.

Morlighem, M., Rignot, E., Seroussi, H., Larour, E., Ben Dhia, H., and Aubry, D.: Spatial patterns of basal drag inferred using control methods from a full-Stokes and simpler models for Pine Island Glacier, West Antarctica, Geophys. Res. Lett., 37, 1-6, https://doi.org/10.1029/2010GL043853, 2010.

Morlighem, M., Rignot, E., Seroussi, H., Larour, E., Ben Dhia, H., and Aubry, D.: A mass conservation approach for mapping glacier ice thickness, Geophys. Res. Lett., 38, 1-6, https://doi.org/10.1029/2011GL048659, 2011.

Morlighem, M., Seroussi, H., Larour, E., and Rignot, E.: Inversion of basal friction in Antarctica using exact and incomplete adjoints of a higher-order model, J. Geophys. Res., 118, 17461753, https://doi.org/10.1002/jgrf.20125, 2013.

Mouginot, J., Rignot, E., and Scheuchl, B.: Sustained increase in ice discharge from the Amundsen Sea Embayment, West Antarctica, from 1973 to 2013, Geophys. Res. Lett., 41, 1-9, https://doi.org/10.1002/2013GL059069, 2014.

Munneke, P. K., Ligtenberg, S. R. M., Van Den Broeke, M. R., and Vaughan, D. G.: Firn air depletion as a precursor of Antarctic ice-shelf collapse, J. Glaciol., 60, 205-214, https://doi.org/10.3189/2014JoG13J183, 2014.

Nakayama, Y., Timmermann, R., M., S., and Hellmer, H.: On the difficulty of modeling Circumpolar Deep Water intrusions onto the Amundsen Sea continental shelf, Ocean Model., 84, 26-34, https://doi.org/10.1016/j.ocemod.2014.09.007, 2014.

Nowicki, S., Bindschadler, R., Abe-Ouchi, A., Aschwanden, A., Bueler, E., Choi, H., Fastook, J., Granzow, G., Greve, R., Gutowski, G., Herzfeld, U., Jackson, C., Johnson, J., Khroulev, C., Larour, E., Levermann, A., Lipscomb, W., Martin, M., Morlighem, M., Parizek, B., Pollard, D., Price, S., Ren, D., Rignot, E., Saito, F., Sato, T., Seddik, H., Seroussi, H., Takahashi, K., Walker, R., and Wang, W.: Insights into spatial sensitivities of ice mass response to environmental change from the SeaRISE ice sheet modeling project II: Greenland, J. Geophys. Res., 118, 1-20, https://doi.org/10.1002/jgrf.20076, 2013a.

Nowicki, S., Bindschadler, R. A., Abe-Ouchi, A., Aschwanden, A., Bueler, E., Choi, H., Fastook, J., Granzow, G., Greve, R., Gutowski, G., Herzfeld, U., Jackson, C., Johnson, J., Khroulev, C., Larour, E., Levermann, A., Lipscomb, W. H., Martin, M. A., Morlighem, M., Parizek, B. R., Pollard, D., Price, S. F., Ren, D., Rignot, E., Saito, F., Sato, T., Seddik, H., Seroussi, H., Takahashi, K., Walker, R., and Wang, W. L.: Insights into spatial sensitivities of ice mass response to environmental change from the SeaRISE ice sheet modeling project I: Antarctica, J. Geophys. Res., 118, 1-23, https://doi.org/10.1002/jgrf.20081, 2013b.

Nowicki, S., Payne, A., Larour, E., Seroussi, H., Goelzer, H., Lipscomb, W., Gregory, J., Abe-Ouchi, A., and Shepherd, A.: Ice Sheet Model Intercomparison Project (ISMIP6) contribution to CMIP6 , Geosci. Model Dev., 9, 4521-4545, https://doi.org/10.5194/gmd-9-4521-2016, 2016.

Palerme, C., Genthon, C., Claud, C., Kay, J., Wood, N., and L'Ecuyer, T.: Evaluation of current and projected Antarctic precipitation in CMIP5 models, Clim. Dynam., 48, 225-239, https://doi.org/10.1007/s00382-016-3071-1, 2016.
Paolo, F., Fricker, H., and Padman, L.: Volume loss from Antarctic ice shelves is accelerating, Science, 348, 6232, 327-331, https://doi.org/10.1126/science.aaa0940, 2015.

Pattyn, F.: A new three-dimensional higher-order thermomechanical ice sheet model: Basic sensitivity, ice stream development, and ice flow across subglacial lakes, J. Geophys. Res., 108, 115, https://doi.org/10.1029/2002JB002329, 2003.

Pattyn, F.: Antarctic subglacial conditions inferred from a hybrid ice sheet/ice stream model, Earth Planet. Sc. Lett., 295, 451-461, https://doi.org/10.1016/j.epsl.2010.04.025, 2010.

Pattyn, F.: Sea-level response to melting of Antarctic ice shelves on multi-centennial timescales with the fast Elementary Thermomechanical Ice Sheet model (f.ETISh v1.0), The Cryosphere, 11, 1851-1878, https://doi.org/10.5194/tc-11-1851-2017, 2017.

Pattyn, F., Schoof, C., Perichon, L., Hindmarsh, R. C. A., Bueler, E., de Fleurian, B., Durand, G., Gagliardini, O., Gladstone, R., Goldberg, D., Gudmundsson, G. H., Huybrechts, P., Lee, V., Nick, F. M., Payne, A. J., Pollard, D., Rybak, O., Saito, F., and Vieli, A.: Results of the Marine Ice Sheet Model Intercomparison Project, MISMIP, The Cryosphere, 6, 573-588, https://doi.org/10.5194/tc-6-573-2012, 2012.

Pattyn, F., Perichon, L., Durand, G., Favier, L., Gagliardini, O., Hindmarsh, R. C. A., Zwinger, T., Albrecht, T., Cornford, S., Docquier, D., Fuerst, J., Goldberg, D., Gudmundsson, H., Humbert, A., Hutten, M., Huybrecht, P., Jouvet, G., Kleiner, T., Larour, E., Martin, D., Morlighem, M., Payne, A., Pollard, D., Ruckamp, M., Rybak, O., Seroussi, H., Thoma, M., and Wilkens, N.: Grounding-line migration in plan-view marine ice-sheet models: results of the ice2sea MISMIP3d intercomparison, J. Glaciol., 59, 410-422, https://doi.org/10.3189/2013JoG12J129, 2013.

Pattyn, F., Favier, L., Sun, S., and Durand, G.: Progress in $\mathrm{Nu}-$ merical Modeling of Antarctic Ice-Sheet Dynamics, Curr. Clim. Change Rep., 3, 174-184, https://doi.org/10.1007/s40641-0170069-7, 2017.

Payne, A., Vieli, A., Shepherd, A., Wingham, D., and Rignot, E.: Recent dramatic thinning of largest West Antarctic ice stream triggered by oceans, Geophys. Res. Lett., 31, 1-4, https://doi.org/10.1029/2004GL021284, 2004.

Perego, M., Price, S., and Stadler, G.: Optimal initial conditions for coupling ice sheet models to Earth system models, J. Geophys. Res.-Earth, 119, 1-24, https://doi.org/10.1002/2014JF003181, 2014.

Petit, J., Jouzel, J., Raynaud, D., Barkov, N., Barnola, J., Basile, I., Bender, M., Chappellaz, J., Davis, M., Delaygue, G., Delmotte, M., Kotlyakov, V., Legrand, M., Lipenkov, V., Lorius, C., Pepin, L., Ritz, C., Saltzman, E., and Stievenard, M.: Climate and atmospheric history of the past 420,000 years from the Vostok ice core, Antarctica, Nature, 399, 429-436, https://doi.org/10.1038/20859, 1999.

Pfeiffer, M. and Lohmann, G.: Greenland Ice Sheet influence on Last Interglacial climate: global sensitivity studies performed with an atmosphere-ocean general circulation model, Clim. Past, 12, 1313-1338, https://doi.org/10.5194/cp-12-1313-2016, 2016.

Pollard, D. and DeConto, R. M.: A simple inverse method for the distribution of basal sliding coefficients under ice sheets, applied to Antarctica, The Cryosphere, 6, 953-971, https://doi.org/10.5194/tc-6-953-2012, 2012a. 
Pollard, D. and DeConto, R. M.: Description of a hybrid ice sheetshelf model, and application to Antarctica, Geosci. Model Dev., 5, 1273-1295, https://doi.org/10.5194/gmd-5-1273-2012, 2012b.

Pollard, D., DeConto, R. M., and Alley, R. B.: Potential Antarctic Ice Sheet retreat driven by hydrofracturing and ice cliff failure, Earth Planet Sc. Lett., 412, 112-121, https://doi.org/10.1016/j.eps1.2014.12.035, 2015.

Pollard, D., Chang, W., Haran, M., Applegate, P., and DeConto, R.: Large ensemble modeling of the last deglacial retreat of the West Antarctic Ice Sheet: comparison of simple and advanced statistical techniques, Geosci. Model Dev., 9, 1697-1723, https://doi.org/10.5194/gmd-9-1697-2016, 2016.

Pritchard, H. D., Ligtenberg, S. R. M., Fricker, H. A., Vaughan, D. G., van den Broeke, M. R., and Padman, L.: Antarctic ice-sheet loss driven by basal melting of ice shelves, Nature, 484, 502-505, https://doi.org/10.1038/nature10968, 2012.

Purucker, M. E.: Geothermal heat flux data set based on low resolution observations collected by the CHAMP satellite between 2000 and 2010, and produced from the MF-6 model following the technique described in Fox Maule et al. (2005), available at: http://websrv.cs.umt.edu/isis/index.php/Antarctica_ Basal_Heat_Flux (last access: 9 May 2019), 2012.

Quiquet, A., Dumas, C., Ritz, C., Peyaud, V., and Roche, D. M.: The GRISLI ice sheet model (version 2.0): calibration and validation for multi-millennial changes of the Antarctic ice sheet, Geosci. Model Dev., 11, 5003-5025, https://doi.org/10.5194/gmd-115003-2018, 2018.

Reeh, N.: Parameterization of melt rate and surface temperature on the Greenland Ice Sheet, Polarforschung, 59, 113-128, hdl:10013/epic.13107, 1991.

Reerink, T. J., Kliphuis, M. A., and van de Wal, R. S. W.: Mapping technique of climate fields between GCM's and ice models, Geosci. Model Dev., 3, 13-41, https://doi.org/10.5194/gmd3-13-2010, 2010.

Reerink, T. J., van de Berg, W. J., and van de Wal, R. S. W.: OBLIMAP 2.0: a fast climate model-ice sheet model coupler including online embeddable mapping routines, Geosci. Model Dev., 9, 4111-4132, https://doi.org/10.5194/gmd-9-4111-2016, 2016.

Reese, R., Albrecht, T., Mengel, M., Asay-Davis, X., and Winkelmann, R.: Antarctic sub-shelf melt rates via PICO, The Cryosphere, 12, 1969-1985, https://doi.org/10.5194/tc-12-19692018, 2018.

Rignot, E., Mouginot, J., and Scheuchl, B.: Ice Flow of the Antarctic Ice Sheet, Science, 333, 1427-1430, https://doi.org/10.1126/science.1208336, 2011a.

Rignot, E., Velicogna, I., van den Broeke, M., Monaghan, A., and Lenaerts, J.: Acceleration of the contribution of the Greenland and Antarctic ice sheets to sea level rise, Geophys. Res. Lett., 38, 1-5, https://doi.org/10.1029/2011GL046583, 2011 b.

Rignot, E., Jacobs, S., Mouginot, J., and Scheuchl, B.: Ice shelf melting around Antarctica, Science, 341, 266-270, https://doi.org/10.1126/science.1235798, 2013.

Rignot, E., Mouginot, J., Morlighem, M., Seroussi, H., and Scheuchl, B.: Widespread, rapid grounding line retreat of Pine Island, Thwaites, Smith and Kohler glaciers, West Antarctica from 1992 to 2011, Geophys. Res. Lett., 41, 3502-3509, https://doi.org/10.1002/2014GL060140, 2014.
Ritz, C.: Un modele thermo-mecanique d'evolution pour le bassin glaciaire antarctique Vostok-Glacier Byrd: Sensibilite aux valeurs des parametres mal connus, Ph.D. thesis, Universite Joseph-Fourier - Grenoble I, 1992.

Ritz, C., Fabre, A., and Letreguilly, A.: Sensitivity of a Greenland ice sheet model to ice flow and ablation parameters: Consequences for the evolution through the last climatic cycle, Clim. Dynam., 13, 11-24, 1997.

Ritz, C., Rommelaere, V., and Dumas, C.: Modeling the evolution of Antarctic ice sheet over the last 420,000 years: Implications for altitude changes in the Vostok region, J. Geophys. Res., 106, 31943-31964, https://doi.org/10.1029/2001JD900232, 2001.

Ritz, C., Edwards, T., Durand, G., Payne, A., V., P., and Hindmarsh, R.: Potential sea-level rise from Antarctic ice-sheet instability constrained by observations, Nature, 528, 115-118, https://doi.org/10.1038/nature16147, 2015.

Rommelaere, V.: EISMINT: Ice shelf models intercomparison, setup of the experiments, Laboratoire de Glaciologie et Geophysique de l'Environnement, 54, rue Moliere BP 9638402 Saint Martin d'Heres cedex FRANCE, 1996.

Rott, H., Rack, W., Skvarca, P., and De Angelis, H.: Northern Larsen Ice Shelf, Antarctica: further retreat after collapse, Ann. Glaciol., 34, 277-282, https://doi.org/10.3189/172756402781817716, 2002.

Sato, T. and Greve, R.: Sensitivity experiments for the Antarctic ice sheet with varied sub-ice-shelf melting rates, Ann. Glaciol., 53, 221-228, https://doi.org/10.3189/2012AoG60A042, 2012.

Scambos, T., Hulbe, C., Fahnestock, M., and Bohlander, J.: The link between climate warming and break-up of ice shelves in the Antarctic Peninsula, J. Glaciol., 46, 516-530, 2000.

Scambos, T., Bohlander, J., Shuman, C., and Skvarca, P.: Glacier acceleration and thinning after ice shelf collapse in the Larsen B embayment, Antarctica, Geophys. Res. Lett., 31, 1-4, https://doi.org/10.1029/2004GL020670, 2004.

Scheuchl, B., Mouginot, J., Rignot, E., Morlighem, M., and Khazendar, A.: Grounding line retreat of Pope, Smith, and Kohler Glaciers, West Antarctica, measured with Sentinel-1a radar interferometry data, Geophys. Res. Lett., 43, 8572-8579, https://doi.org/10.1002/2016GL069287, 2016.

Schlegel, N.-J., Larour, E., Seroussi, H., Morlighem, M., and Box, J. E.: Decadal-scale sensitivity of Northeast Greenland ice flow to errors in surface mass balance using ISSM, J. Geophys. Res.Earth, 118, 667-680, https://doi.org/10.1002/jgrf.20062, 2013.

Schlegel, N.-J., Larour, E., Seroussi, H., Morlighem, M., and Box, J. E.: Ice discharge uncertainties in Northeast Greenland from boundary conditions and climate forcing of an ice flow model, J. Geophys. Res.-Earth, 120, 29-54, https://doi.org/10.1002/2014JF003359, 2015.

Schlegel, N.-J., Seroussi, H., Schodlok, M. P., Larour, E. Y., Boening, C., Limonadi, D., Watkins, M. M., Morlighem, M., and van den Broeke, M. R.: Exploration of Antarctic Ice Sheet 100-year contribution to sea level rise and associated model uncertainties using the ISSM framework, The Cryosphere, 12, 3511-3534, https://doi.org/10.5194/tc-12-3511-2018, 2018.

Schmidtko, S., Heywood, K., Thompson, A., and Aoki, S.: Multidecadal warming of Antarctic waters, Science, 346, 1227-1231, https://doi.org/10.1126/science.1256117, 2014.

Schodlok, M., Menemenlis, D., and Rignot, E.: Ice shelf basal melt rates around Antarctica from simulations 
and observations, J. Geophys. Res., 121, 1085-1109, https://doi.org/10.1002/2015JC011117, 2016.

Schoof, C.: The effect of cavitation on glacier sliding, Proc. R. Soc. A, 461, 609-627, https://doi.org/10.1098/rspa.2004.1350, 2005.

Schoof, C.: A variational approach to ice stream flow, J. Fluid Mech., 556, 227-251, https://doi.org/10.1017/S0022112006009591, 2006.

Schoof, C.: Ice sheet grounding line dynamics: Steady states, stability, and hysteresis, J. Geophys. Res., 112, 1-19, https://doi.org/10.1029/2006JF000664, 2007.

Seroussi, H. and Morlighem, M.: Representation of basal melting at the grounding line in ice flow models, The Cryosphere, 12, 3085-3096, https://doi.org/10.5194/tc-12-3085-2018, 2018.

Seroussi, H., Morlighem, M., Rignot, E., Larour, E., Aubry, D., Ben Dhia, H., and Kristensen, S. S.: Ice flux divergence anomalies on 79north Glacier, Greenland, Geophys. Res. Lett., 38, L09501, https://doi.org/10.1029/2011GL047338, 2011.

Seroussi, H., Morlighem, M., Rignot, E., Khazendar, A., Larour, E., and Mouginot, J.: Dependence of century-scale projections of the Greenland ice sheet on its thermal regime, J. Glaciol., 59, 1024-1034, https://doi.org/10.3189/2013JoG13J054, 2013.

Seroussi, H., Morlighem, M., Rignot, E., Mouginot, J., Larour, E., Schodlok, M. P., and Khazendar, A.: Sensitivity of the dynamics of Pine Island Glacier, West Antarctica, to climate forcing for the next 50 years, The Cryosphere, 8, 1699-1710, https://doi.org/10.5194/tc-8-1699-2014, 2014.

Seroussi, H., Nakayama, Y., Larour, E., Menemenlis, D., Morlighem, M., Rignot, E., and Khazendar, A.: Continued retreat of Thwaites Glacier, West Antarctica, controlled by bed topography and ocean circulation, Geophys. Res. Lett., 44, 6191-6199, https://doi.org/10.1002/2017GL072910, 2017.

Shapiro, N. M. and Ritzwoller, M. H.: Inferring surface heat flux distributions guided by a global seismic model: particular application to Antarctica, Earth Planet. Sc. Lett., 223, 213-224, https://doi.org/10.1016/j.epsl.2004.04.011, 2004.

Sutter, J., Gierz, P., Grosfeld, K., Thoma, M., and Lohmann, G.: Ocean temperature thresholds for Last Interglacial West Antarctic Ice Sheet collapse, Geophys. Res. Lett., 43, 2675-2682, https://doi.org/10.1002/2016GL067818, 2016.

Taylor, K., Stouffer, R., and Meehl, G.: An Overview of CMIP5 and the experiment design, Bull. Am. Math. Soc., 93, 485-498, https://doi.org/10.1175/BAMS-D-11-00094.1, 2012.

Thomas, R., Rignot, E., Casassa, G., Kanagaratnam, P., Acuna, C., Akins, T., Brecher, H., Frederick, E., Gogineni, P., Krabill, W., Manizade, S., Ramamoorthy, H., Rivera, A., Russell, R., Sonntag, J., Swift, R., Yungel, J., and Zwally, J.: Accelerated sea-level rise from West Antarctica, Science, 306, 255-258, https://doi.org/10.1126/science.1099650, 2004.
Tsai, V., Stewart, A., and Thompson, A.: Marine ice-sheet profiles and stability under Coulomb basal conditions, J. Glaciol., 61, 205-215, https://doi.org/10.3189/2015JoG14J221, 2015.

van Wessem, J. M., Reijmer, C. H., Morlighem, M., Mouginot, J., Rignot, E., Medley, B., Joughin, I., Wouters, B., Depoorter, M. A., Bamber, J. L., Lenaerts, J. T. M., van de Berg, W. J., van den Broeke, M. R., and van Meijgaard, E.: Improved representation of East Antarctic surface mass balance in a regional atmospheric climate model, J. Glaciol., 60, 761-770, https://doi.org/10.3189/2014JoG14J051, 2014.

van Wessem, J. M., Van De Berg, W. J., Noël, B. P. Y., Van Meijgaard, E., Amory, C., Birnbaum, G., Jakobs, C. L., Krüger, K. Lenaerts, J., Lhermitte, S., Ligtenberg, S. R. M., Medley, B., Reijmer, C. H., van Tricht, K., Trusel, L. D., van Ulft, L. H., Wouters, B., Wuite, J., and van den Broeke, M. R.: Modelling the climate and surface mass balance of polar ice sheets using RACMO2 Part 2: Antarctica (1979-2016), The Cryosphere, 12, 1479-1498, https://doi.org/10.5194/tc-12-1479-2018, 2018.

Vaughan, D. G. and Doake, C. S. M.: Recent atmospheric warming and retreat of ice shelves on the Antarctic Peninsula, Nature, 379 , 328-331, 1996.

Waelbroeck, C., Labeyrie, L., Michel, E., Duplessy, J. C., McManus, J. F., Lambeck, K., Balbon, E., and Labracherie, M.: Sealevel and deep water temperature changes derived from benthic foraminifera isotopic records, Quaternary Sci. Rev., 21, 295-305, https://doi.org/10.1016/S0277-3791(01)00101-9, 2002.

Weertman, J.: On the sliding of glaciers, J. Glaciol., 3, 33-38, 1957.

Winkelmann, R., Martin, M. A., Haseloff, M., Albrecht, T., Bueler, E., Khroulev, C., and Levermann, A.: The Potsdam Parallel Ice Sheet Model (PISM-PIK) - Part 1: Model description, The Cryosphere, 5, 715-726, https://doi.org/10.5194/tc-5-715-2011, 2011.

Wouters, B., Martin-Espanol, A., Helm, V., Flament, T., van Wessem, J. M., Ligtenberg, S. R. M., van den Broeke, M. R., and Bamber, J. L.: Dynamic thinning of glaciers on the Southern Antarctic Peninsula, Science, 348, 899-903, https://doi.org/10.1126/science.aaa5727, 2015.

Zhang, X., Lohmann, G., Knorr, G., and Purcell, C.: Abrupt glacial climate shifts controlled by ice sheet changes, Nature, 512, 7514, https://doi.org/10.1038/nature13592, 2014. 